\title{
Gadd $45 \beta$ promotes hepatocyte survival during liver regeneration in mice by modulating JNK signaling
}

\author{
Salvatore Papa, ${ }^{1}$ Francesca Zazzeroni, ${ }^{1}$ Yang-Xin Fu, ${ }^{2}$ Concetta Bubici, ${ }^{1}$ Kellean Alvarez, ${ }^{1}$ \\ Kathryn Dean, ${ }^{1}$ Peter A. Christiansen, ${ }^{2}$ Robert A. Anders, ${ }^{2}$ and Guido Franzoso ${ }^{1}$
}

${ }^{1}$ Ben May Department for Cancer Research and 2Department of Pathology, University of Chicago, Chicago, Illinois, USA.

\begin{abstract}
In the liver, the JNK cascade is induced downstream of TNF receptors (TNFRs) in response to inflammatory, microbial, and toxic challenges. Sustained activation of JNK triggers programmed cell death (PCD), and hepatocyte survival during these challenges requires induction of the NF- $\mathrm{KB}$ pathway, which antagonizes this activation by upregulating target genes. Thus, modulation of JNK activity is crucial to the liver response to TNFR-mediated challenge. The basis for this modulation, however, is unknown. Here, we investigated the role of the NF- $\kappa \mathrm{B}$ target Gadd $45 \mathrm{~b}$ in the regulation of hepatocyte fate during liver regeneration after partial hepatectomy. We generated $\mathrm{Gadd} 45 \mathrm{~b}^{-/-}$mice and found that they exhibited decreased hepatocyte proliferation and increased PCD during liver regeneration. Notably, JNK activity was markedly increased and sustained in livers of Gadd45 $b^{-/-}$mice compared with control animals after partial hepatectomy. Furthermore, imposition of a Jnk2-null mutation, attenuating JNK activity, completely rescued the regenerative response in $\mathrm{Gadd}_{45 b^{-/-}}$mice. Interestingly, Gadd $45 \beta$ ablation did not affect hepatotoxic JNK signaling after a TNFR-mediated immune challenge, suggesting specificity in the inducible hepatic program for JNK restraint activated during distinct TNFR-mediated challenges. These data provide a basis for JNK suppression during liver regeneration and identify Gadd $45 \beta$ as a potential therapeutic target in liver diseases.
\end{abstract}

\section{Introduction}

TNF- $\alpha$ is a pleiotropic cytokine that plays important roles in immunity, inflammation, and tumorigenesis $(1,2)$. Exposure to TNF- $\alpha$ induces either cell proliferation or programmed cell death (PCD) through the engagement of its 2 receptors: TNF receptor 1 (TNFR1) and TNFR2. Cell survival following the triggering of these receptors depends on the activation of NF-KB family transcription factors (2), and this NF- $\mathrm{KB}$-afforded antagonism of TNF- $\alpha$-induced PCD is crucial for organismal physiology, chronic inflammation, and carcinogenesis (2-4). We and others previously showed that this antagonism involves a suppression of the sustained activation of the JNK cascade, a major MAPK cascade in eukaryotes $(5,6)$. Indeed, whereas in most systems, transient activation of this cascade signals cell growth and differentiation, its prolonged activation triggers $\operatorname{PCD}(2,4)$. Thus, the biological outcome of the stimulation of TNFRs is dictated in part by the balance between the opposing activities of NF-KB and JNK.

The relevance of this crosstalk between NF- $\mathrm{KB}$ and JNK to cell fate is best documented in the liver $(4,7,8)$. Targeted deletion of NF- $\mathrm{kB} / \mathrm{RelA}$ or of the NF- $\kappa B$-activating kinases inhibitor of $\kappa B$ kinase $\beta$ (IKK $\beta$ ) and IKK $\gamma /$ NEMO causes liver apoptosis, and this apoptosis is inhibited by the compound mutation of TNFR1 (or TNF- $\alpha$ ) or of the JNK isoform JNK1 $(2,9)$. NF- $\mathrm{kB}$ and JNK fulfill similar hepatoprotective and hepatotoxic roles, respectively, in the adult

Nonstandard abbreviations used: BHA, butylated hydroxyanisole; $\mathrm{CN}$, coagulative necrosis; ConA, concanavalin A; dKO, double KO; Gadd45 $\beta$, growth arrest and DNAdamage-inducible gene $45 \beta$; HGF, hepatocyte growth factor; IKB $\alpha \mathrm{M}$, inhibitor of $\kappa \mathrm{B} \alpha$ mutant; IKK, inhibitor of $\kappa \mathrm{B}$ kinase; MKK7/JNKK2, MAPK kinase 7/JNK kinase 2 ; NPC, nonparenchymal cell; PARP-1, poly(ADP) ribose polymerase-1; PCD, programmed cell death; $\mathrm{PH}$, partial hepatectomy; TEM, transmission electron microscopy; TNFR, TNF receptor.

Conflict of interest: The authors have declared that no conflict of interest exists. Citation for this article: J. Clin. Invest. 118:1911-1923 (2008). doi:10.1172/JCI33913.

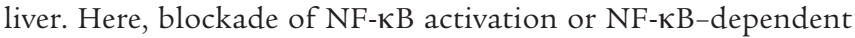
transcription markedly enhances TNFR-induced JNK signaling and hepatic injury during systemic challenge with concanavalin A (ConA), LPS, or TNF- $\alpha$ (10-12), and suppression of this signaling effectively blunts this injury in NF-KB-deficient mice $(7,9,11,13)$.

TNFR1 is also a potent inducer of hepatocyte proliferation (14). Almost unique among mammalian organs, the liver possesses marked regenerative capacity. Following partial hepatectomy (PH), quiescent hepatocytes synchronously exit $\mathrm{G}_{0}$ and divide once or twice until the original liver mass is restored $(15,16)$. The earliest step in this process is the priming of hepatocytes, which enables these cells to enter $G_{1}$ and respond to mitogens such as hepatocyte growth factor (HGF) and TGF- $\alpha(14,16)$. This process is chiefly orchestrated by TNFR1, which triggers the sequential induction of NF-KB and IL-6 $(14,16)$.

PH-elicited TNFR1 stimulation also induces JNK activation (15), and blockade of this activation severely hinders hepatocyte DNA replication during liver regeneration (17). A similar impairment was reported in mice harboring hepatocyte-specific mutation of the JNK target c-Jun (18). Hence, whereas sustained JNK activation - as elicited in NF-kB-deficient models by ConA or LPS - triggers hepatocyte PCD, transient JNK activation - as normally induced by $\mathrm{PH}-$ is required for hepatocyte proliferation, an action mediated by site-specific c-Jun phosphorylation $(2,4,7,8)$. These findings suggest that whether a hepatocyte will proliferate or die in response to TNFR-mediated challenge is dictated in part by the magnitude and duration of JNK activation induced by this challenge.

As in other tissues, activity of the JNK cascade in the liver is under NF-אB transcriptional control $(2,7,8)$. Putative mediators of this NF-KB-JNK crosstalk were previously identified in in vitro studies, and we implicated the NF- $\mathrm{KB}$ target growth arrest and DNA-damage-inducible gene $45 \beta$ (Gadd $45 b$ ) as one of such 

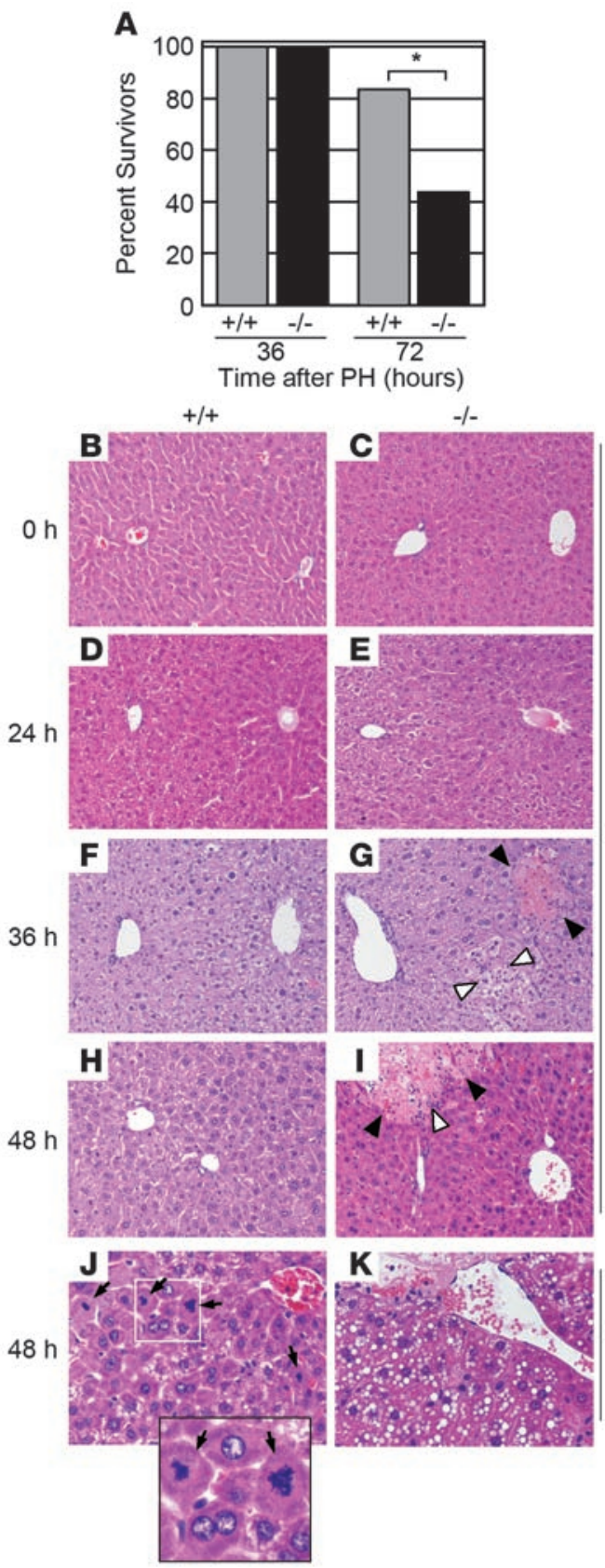

L

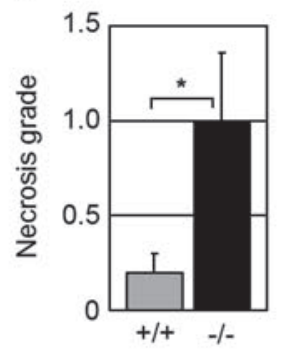

N

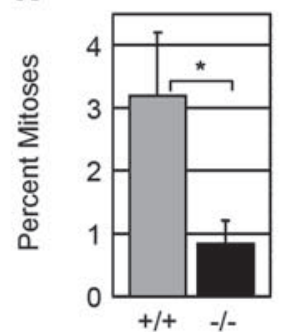

M

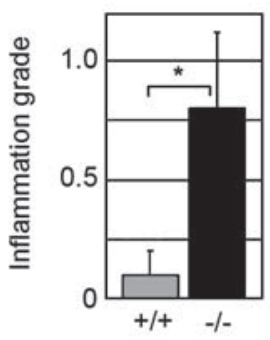

0

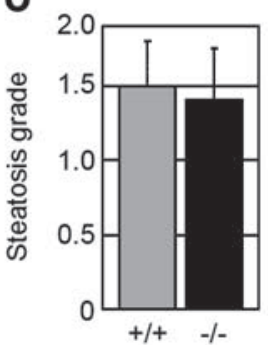

P

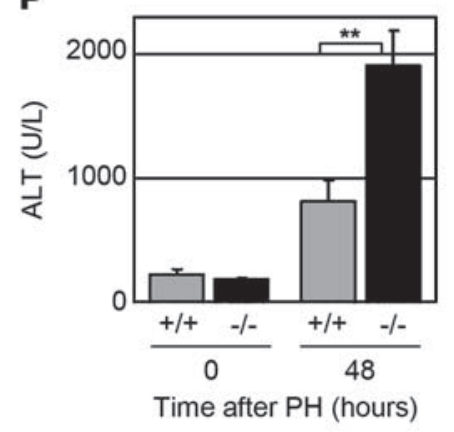

Q

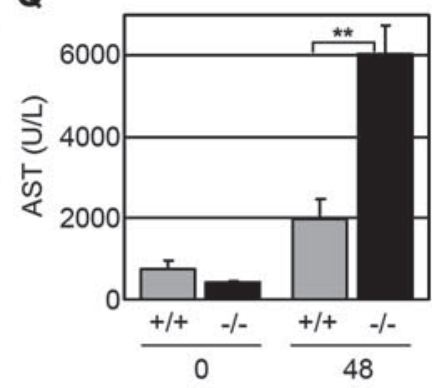

Time after $\mathrm{PH}$ (hours)

\section{Figure 1}

Impaired liver regeneration in Gadd45 $b^{-/-}$mice. (A) Percent survival in Gadd45b+/+ $(+/+)$and Gadd45 $b^{-/-}(-/-)$mice $(n=12)$ at the indicated times after PH. ${ }^{*} P<0.05$, log-rank test. (B-K) Images of H\&E-stained liver sections from representative Gadd $45 b^{+/+}$and Gadd $45 b^{-/-}$mice at the indicated times after PH. Original magnification: $\times 20$ (B-I); $\times 40$ ( $\mathbf{J}$ and $\mathbf{~ K}) ; \times 40$ (J, inset). 0 h, untreated; black arrowheads, necrosis; white arrowheads, inflammatory infiltrates; black arrows (J), mitotic figures. (L) Necrosis grade in livers of Gadd $45 b^{+/+}$and $G a d d 45 b^{-/-}$mice $(n=10)$ 48 hours after $\mathrm{PH}$. Values are mean \pm SEM. ${ }^{*} P<0.05$. (M) Inflammation grade in the same livers used in $\mathrm{L}$. Values are mean $\pm \mathrm{SEM}$. ${ }^{*} P<0.05$. (N) Percent mitosis in livers of Gadd45 $b^{+/+}$and Gadd45 $b^{-/-}$mice $(n=27) 48$ hours after PH. Values are mean \pm SEM. ${ }^{\star} P<0.05$. $(\mathbf{O})$ Steatosis grade in the same livers used in $\mathbf{L}$. Values are mean \pm SEM. Alanine transaminase (ALT) (P) and aspartate transaminase (AST) (Q) activities in sera of Gadd $45 b^{+/+}$and Gadd $45 b^{-/-}$mice prior to $(0 ; n=3)$ or 48 hours after $(n=14) \mathrm{PH}$. Values are mean \pm SEM. ${ }^{* \star} P<0.01$.

putative mediators $(5,19)$. We reported that Gadd $45 \beta$ is induced rapidly by TNF- $\alpha$ through a mechanism that requires NF- $\kappa B$ and

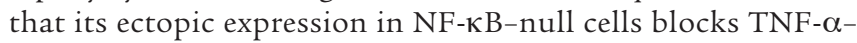
elicited, sustained JNK signaling and PCD. How the inducible control of sustained JNK signaling is exercised, in vivo, and the biological relevance (if any) of the aforementioned genes to this control, however, are not known.

Gadd $45 b$ is induced rapidly by $\mathrm{PH}(20,21)$. Thus, to investigate the role of Gadd $45 \beta$ in liver regeneration and understand the mechanism(s) controlling JNK activation in vivo, we generated 
A

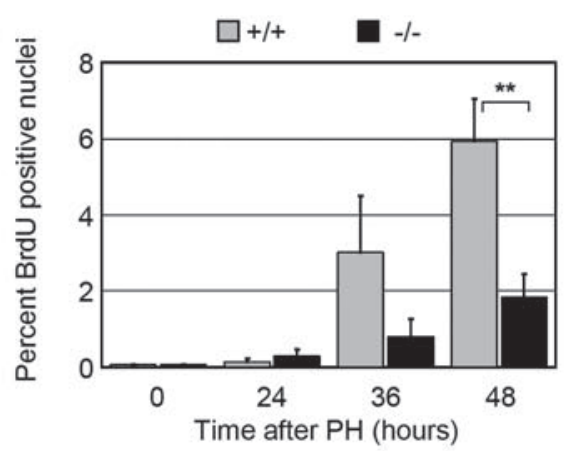

C

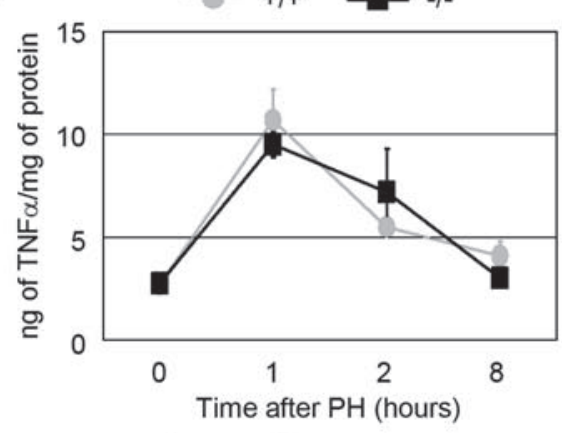

E

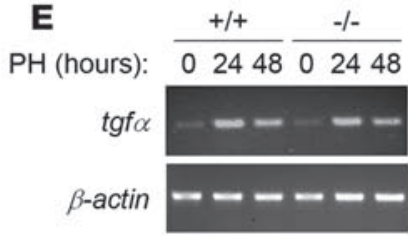

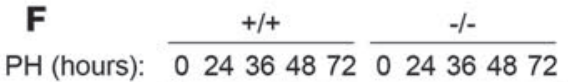

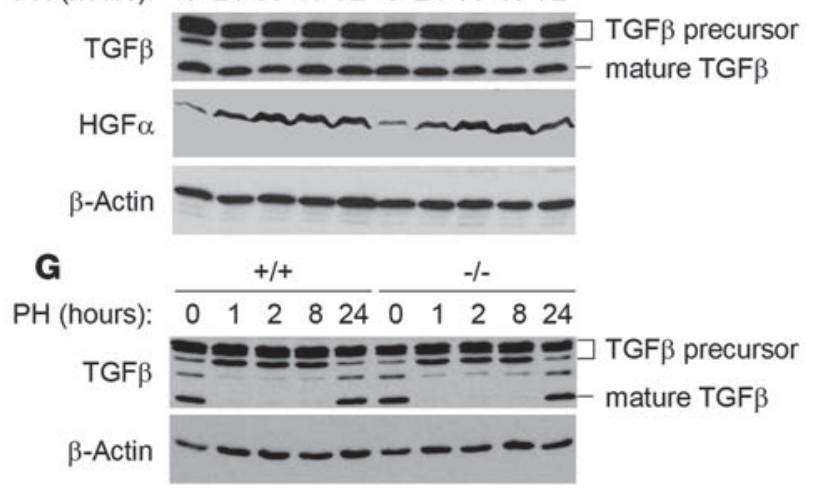

B

$\mathrm{Oh}$

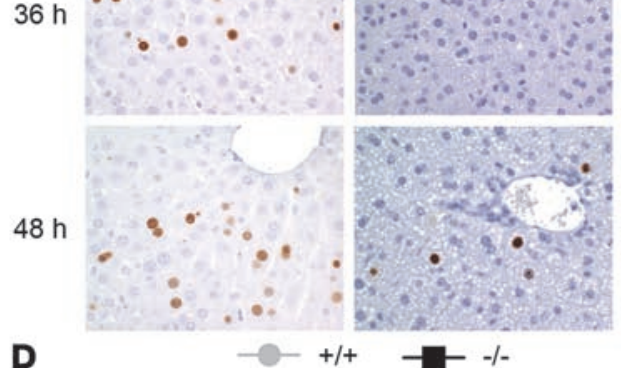

D

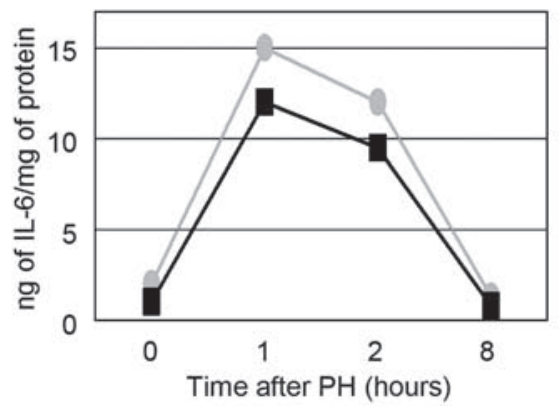

H

PH (hours): $0 2 4 3 6 4 8 7 2 \longdiv { 0 2 4 3 6 4 8 7 2 }$

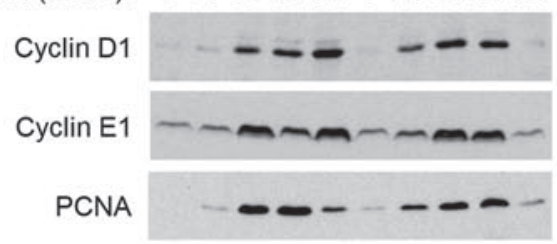

Cyclin A - ニ

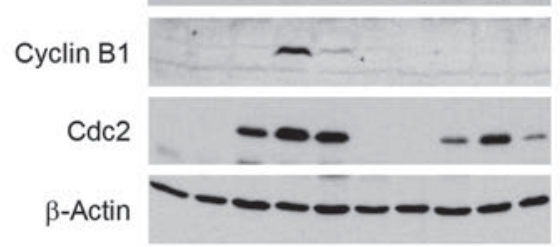

\section{Figure 2}

Impaired hepatocyte proliferation in Gadd45 $b^{-/-}$mice after $\mathrm{PH}$, despite normal cytokine induction. (A) Histomorphometric quantification of BrdU+ nuclei in livers of Gadd45 $b^{+/+}$and Gadd45b $b^{-/}$mice prior to $(n=3)$ or $24(n=4), 36(n=6)$, and 48 hours $(n=20)$ after PH. Values are mean \pm SEM. ${ }^{* \star} P<0.01$. (B) Images of liver sections depicting representative clusters of BrdU+ cells from the mice shown in A. Original magnification, $\times 40$. ELISA showing concentrations of TNF- $\alpha$ (C) and IL-6 (D) in livers of Gadd45b $b^{+/+}$and Gadd $45 b^{-/-}$mice $(n=3)$ at the indicated times after PH.

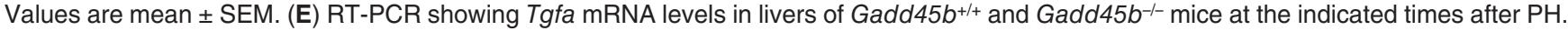
$(\mathbf{F}-\mathrm{H})$ Western blots showing levels of TGF- $\beta, \mathrm{HGF} \alpha$, and cell cycle-regulating proteins in livers of Gadd $45 b^{+/+}$and $\mathrm{Gadd} 45 b^{-/-}$mice at the indicated times after PH. n.s., nonspecific.

Gadd $45 b^{-/-}$mice. Here, we show that Gadd $45 \beta$ is required for liver regeneration. Gadd $45 b^{-1-}$ mice displayed increased mortality and profoundly impaired hepatocyte survival and cell-cycle progression in response to PH. Notably, the abortive regenerative response of these mice was associated with selective deregulation of JNK signaling, and attenuation of this signaling by JNK2 ablation fully corrected this response. Interestingly, Gadd $45 \beta$ ablation had no effect on JNK activity during ConA or LPS challenges, which also 
A

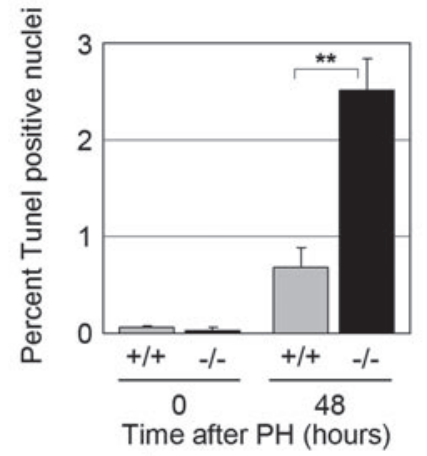
$+/+$

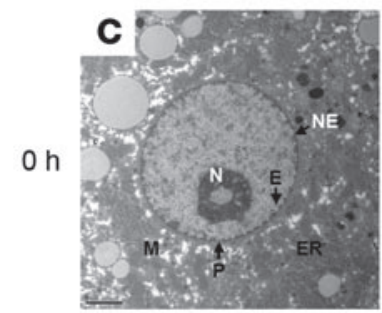

$48 h$

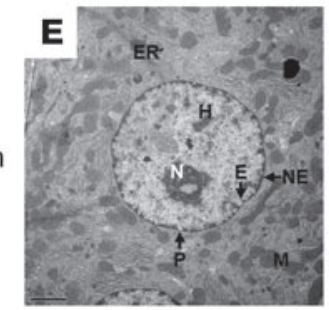

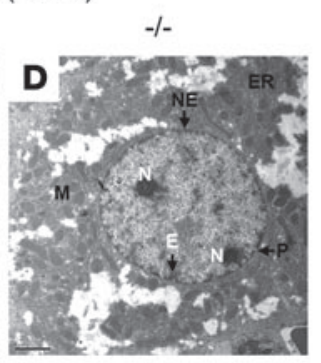

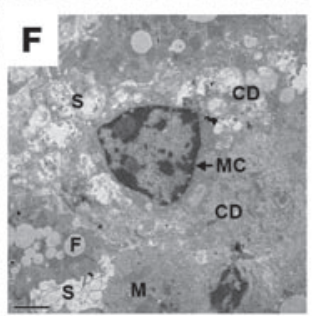

B

$\mathrm{Oh}$

G

$48 \mathrm{~h}$

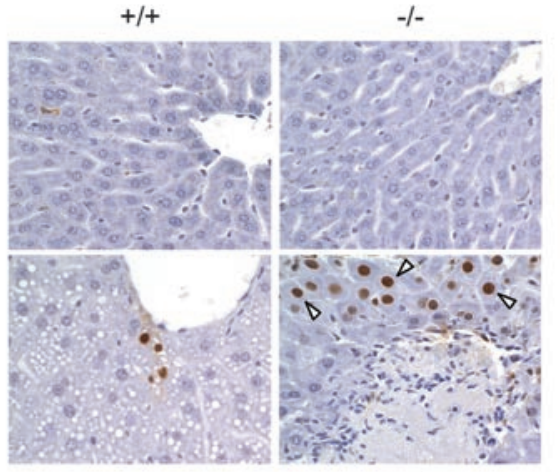

$+/+$
-/-
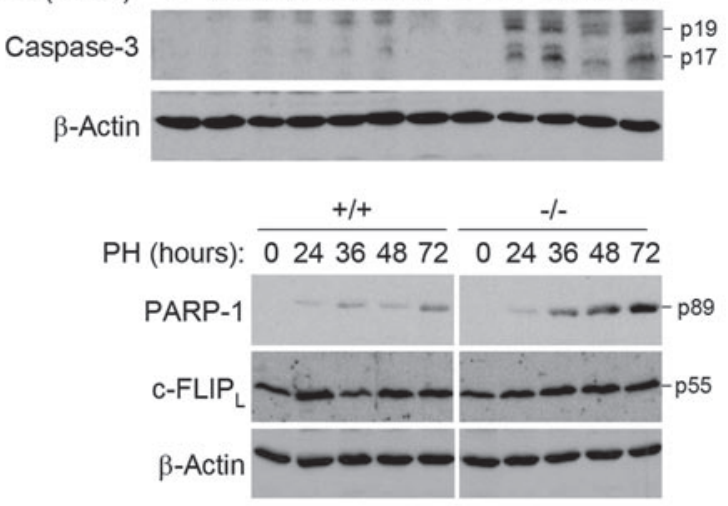

\section{Figure 3}

Increased apoptosis in livers of Gadd45b $b^{-/-}$mice after PH. (A) Histomorphometric quantification of TUNEL nuclei in livers of Gadd45 $b^{+/+}$and Gadd $45 b^{-/-}$mice prior to $(0 ; n=3)$ or 48 hours after $(n=16) \mathrm{PH}$. Values are mean \pm SEM. ${ }^{* *} P<0.01$. (B) Images of liver sections depicting representative clusters of TUNEL+ cells from the mice shown in A. Original magnification, $\times 40$. Open arrowheads, TUNEL+ hepatocytes with evident chromatin condensation. (C-F) TEM images showing hepatocytes from representative Gadd $45 b^{+/+}$and Gadd $45 b^{-/-}$mice prior to (0 hours) and 48 hours after PH. (C and D) Hepatocytes from untreated animals exhibiting a thin nuclear envelop (NE), distinct nucleoli (N), euchromatin (E) associated with the nuclear pores (P), ER, and mitochondria (M). (E) Hepatocyte from a hepatectomized wild-type animal displaying many of the same features of the cells depicted in $\mathbf{C}$ and $\mathbf{D}$. H, heterochromatin. (F) Hepatocyte from a hepatectomized Gadd $45 \mathrm{~b}^{-1-}$ animal displaying signs of necrosis, including cytoplasmic disorganization (CD) with the presence of poorly defined organelles and ER, swollen organelles (S), and only few intact mitochondria. The nucleus shows dense marginated chromatin (MC) and few nuclear pores. F, intracytoplasmic fat. Scale bars: $2 \mu \mathrm{m}$. (G) Western blots showing procaspase-3 and PARP-1 cleavage products and C-FLIP levels in livers of Gadd $45 b^{+/+}$and Gadd $45 b^{-/-}$mice at the indicated times after $\mathrm{PH}$.

inflict hepatic damage through a TNFR-dependent, JNK-mediated mechanism $(7,11)$, thereby establishing specificity in the inducible hepatic program for JNK restraint. These data identify Gadd $45 \beta$ as a crucial contextual modulator of the JNK cascade, and hence of hepatocyte fate, during liver regeneration and provide a paradigm for the basis of JNK suppression in vivo. Indeed, they also have important implications for treatment of widespread liver diseases.

\section{Results}

Generation and initial analyses of Gadd $45 b^{-/-}$mice. To delineate the role(s) of Gadd $45 \beta$ in control of JNK signaling during hepatic challenge, we generated $\mathrm{Gadd} 45 \mathrm{~b}^{-/-}$mice using standard gene-targeting technology in ES cells. Correct homologous recombination of the targeting vector, replacing the entire Gadd $45 \beta$-coding sequence with a neomycin (Neo) cassette (Supplemental Figure 1A; supplemental material available online with this article; doi:10.1172/
JCI33913DS1) - which assured that no functional Gadd $45 \beta$ protein could be produced - was verified by Southern blotting (Supplemental Figure 1B). Four (of 12) correctly integrated Gadd45 $b^{+/-}$ ES clones were microinjected into C57BL/6 blastocysts, and 2 (i.e., G48 and G58) allowed for germline transmission of the mutated allele, yielding independent lines of $\mathrm{Gadd}_{45} \mathrm{~b}^{+/+}$, Gadd45b $\mathrm{b}^{+-}$, and Gadd $45 b^{-/-}$mice (Supplemental Figure 1C), which were indistinguishable in subsequent experiments. Successful disruption of the GADD $45 B$ locus was confirmed by Northern blot and quantitative real-time PCR (QRT-PCR) analyses (data not shown and Supplemental Figure 1D, respectively). Expression of the other Gadd45 family members, Gadd45a and Gadd45g (2), was unaffected by Gadd $45 \beta$ ablation (Supplemental Figure 1E), suggesting that function of their products is retained in Gadd $45 b^{-/-}$mice.

In agreement with previous reports $(22,23)$, Gadd $45 b^{-/-}$mice were born at the expected frequency, developed normally, and displayed 

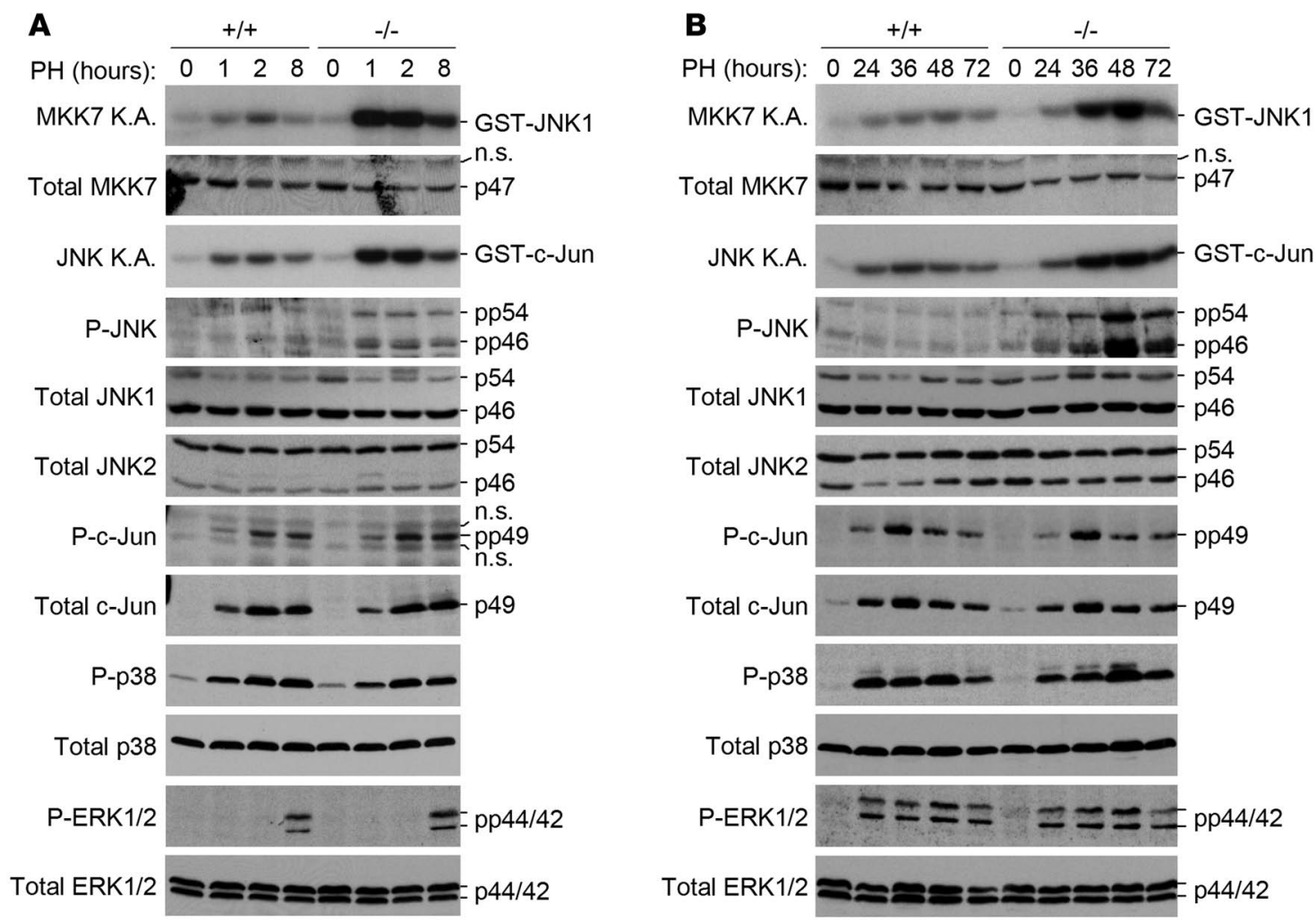

Figure 4

Exacerbated JNK activation in livers of Gadd45 $b^{-/-}$mice after PH. (A and B) Western blots with antibodies against phosphorylated or total kinases and c-Jun, and kinase assays (K.A.) showing MKK7, MAPK, and c-Jun activation in livers of Gadd45b $b^{+/+}$and Gadd45b $b^{-/-}$mice at the indicated times after $\mathrm{PH}$.

no obvious abnormalities on gross and histopathological examinations (data not shown). Analysis of the spleen, lymph nodes, bone marrow, thymus, and liver of these animals also revealed no defects in cell counts and lymphoid or monocyte/macrophage development (data not shown). Significantly, this analysis failed to uncover any abnormality in Gadd $45 b^{-/-}$mice in either hepatic cell development or function (data not shown).

Defective liver regeneration in Gadd456 $b^{-/}$mice. In line with previous reports $(20,21)$, Gadd45b was induced rapidly by PH, persisting at relatively high levels over time (Supplemental Figure 2A). Remarkably, this induction was severely impaired by the ablation of TNFR1 (Supplemental Figure 2B), which governs hepatocyte priming during liver regeneration (14). Hepatic Gadd45b expression was also upregulated by LPS and ConA treatments (Supplemental Figure 2C and Supplemental Figure 6A), which also stimulate TNFRs on hepatocytes $(7,8)$. Hence, Gadd $45 \beta$ is a putative mediator of the TNFR hepatic function.

To assess the role of Gadd $45 \beta$ in this function, we performed PH. As expected, most wild-type mice fully recovered from surgery, exhibiting a high survival rate at 72 hours (Figure 1A). In contrast, survival of Gadd $45 b^{-/-}$mice at this time was only $44 \%$. This high mortality was unlikely due to surgery complications, as survival in both groups of animals was near $100 \%$ at 36 hours. Indeed, livers of hepatectomized $\mathrm{Gadd} 45 b^{-/-}$mice appeared normal at microscopic inspection at early times, showing features of a typical regenerative response, including perturbed lobular architecture and hepatocyte hypertrophy (Figure 1, B-E). By 36 hours, however, most of these livers dis- played signs of injury, including small foci of coagulative necrosis $(\mathrm{CN})$, which increased in size and number at 48 hours (Figure 1, F-I, black arrowheads). The significance of this finding was confirmed by quantitative scoring (Figure 1L). As expected, the onset of necrosis in Gadd $45 b^{-/-}$livers was associated with the appearance of inflammatory infiltrates - not observed in control mice (Figure 1M; see also Figure 1, F-I, white arrowheads). Notably, mutant livers also exhibited a significantly lower frequency of hepatocyte mitotic figures at 48 hours, as compared with controls (Figure 1N; see also Figure 1, $\mathrm{J}$ and $\mathrm{K}$, black arrows). However, no significant difference between the 2 groups of mice was observed in the steatosis grade (Figure 1O). Concomitant with this hepatic injury, Gadd $45 b^{-/}$animals displayed a marked elevation in serum transaminase levels, a sign of hepatocytolysis, whereas this elevation was relatively modest in littermate controls (Figure 1, P and Q). We concluded that TNFR1-induced Gadd $45 \beta$ upregulation is required for hepatoprotection and hepatocyte proliferation during liver regeneration.

Impaired proliferation but relatively normal cell-cycle entry and cytokine expression in Gadd45b-/- livers. To investigate the basis for the defective response of $\mathrm{Gadd} 45 \mathrm{~b}^{-/-}$mice to $\mathrm{PH}$, we monitored hepatocyte proliferation in further detail. As shown in Figure 2, A and B (BrdU incorporation assays), basal hepatic DNA replication was negligible, irrespective of genotype. As expected, however, Gadd $45 b^{+/+}$livers displayed a vigorous proliferative response, beginning 36 hours and peaking 48 hours after $\mathrm{PH}$. In contrast, livers of $\mathrm{Gadd}_{4} \mathrm{bb}^{-/-}$mice contained relatively few $\mathrm{BrdU}^{+}$cells at either of these times (Figure 2, $\mathrm{A}$ and $\mathrm{B})$. Of note, the difference between the 2 groups of mice in 
A

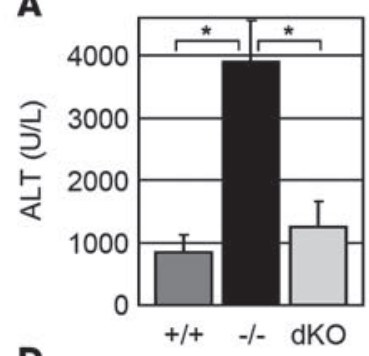

D

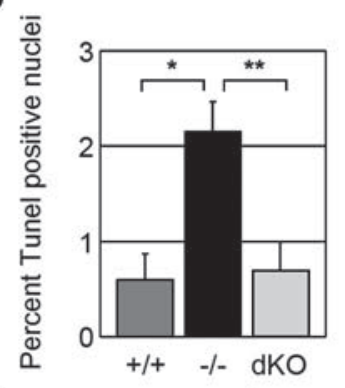

B

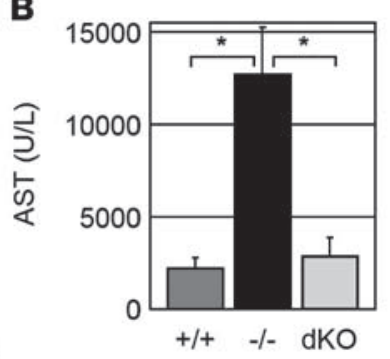

E

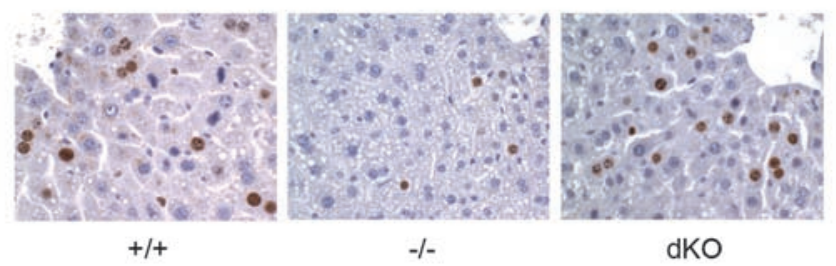

C

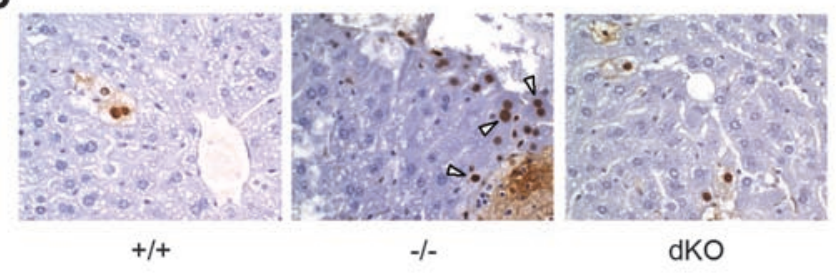

F

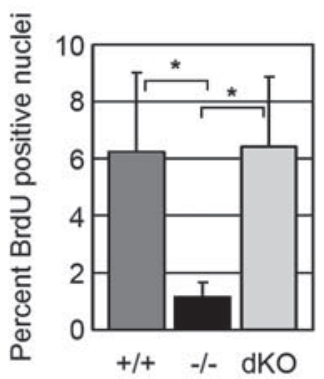

G

$+1+$

$-1-$

dKO

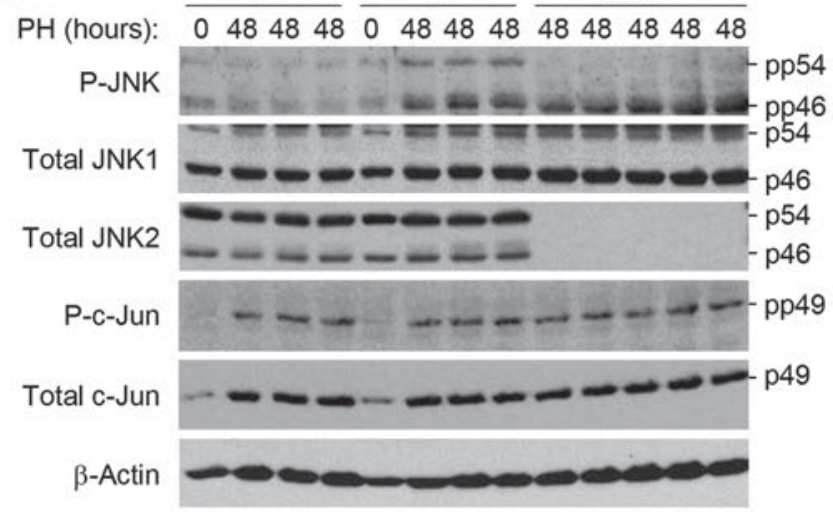

Figure 5

Deletion of JNK2 completely corrects the defective regenerative response of Gadd45b/- mice. ALT (A) and AST (B) activities in sera of

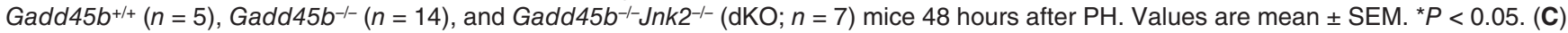
Images of liver sections depicting representative clusters of TUNEL+ cells from the mice shown in $\mathbf{D}$. Original magnification, $\times 40$. White arrowheads, TUNEL+ hepatocytes with evident chromatin condensation. (D) Histomorphometric quantification of TUNEL+ nuclei in livers of Gadd45b/+ $(n=5)$, Gadd45 $b^{-/-}(n=14)$, and Gadd45b-/-Jnk2 ${ }^{-/-}(n=7)$ mice 48 hours after PH. Values are mean \pm SEM. ${ }^{*} P<0.05,{ }^{* \star} P<0.01$. (E) Images of liver sections depicting representative clusters of BrdU+ cells from the mice shown in F. Original magnification, $\times 40$. (F) Histomorphometric quan-

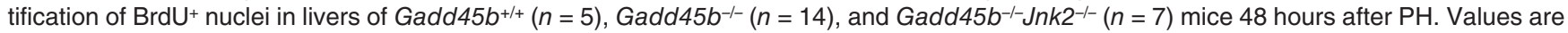
mean \pm SEM. ${ }^{\star} P<0.05$. (G) Western blots with antibodies against phosphorylated or total JNK $1 / 2$ or c-Jun showing JNK and c-Jun activation in

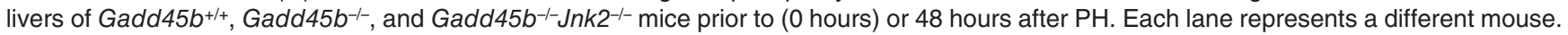

the number of $\mathrm{BrdU}^{+}$cells became most evident with time, reaching statistical significance only at 48 hours (Figure 2A; $P<0.01$; see also 24 and 36 hours, $P=0.39$ and $P=0.30$, respectively). Whereas this could be explained in part by the fewer $\mathrm{BrdU}^{+}$hepatocytes present in wild-type livers at earlier time points, the data suggest that the defective hepatocyte proliferation observed in mutant mice was not a direct consequence of Gadd $45 \beta$ ablation.

Next, we examined whether the abortive proliferative response of Gadd $45 b^{-1-}$ hepatocytes was due to an impaired production of factors known to drive this response (14). In wild-type mice, hepatic TNF- $\alpha$ levels surged rapidly, 1 hour after $\mathrm{PH}$, declining to baseline by 8 hours (Figure 2C). This TNF- $\alpha$ induction profile was unperturbed by Gadd $45 \beta$ ablation (Figure 2C). Similar findings were obtained with IL-6, a key downstream effector of TNF- $\alpha$ (14). It too was upregulated with comparable kinetics in wild-type and Gadd45 $b^{-/-}$livers, coincident with the TNF- $\alpha$ surge (Figure 2D). Other key regulators of $\mathrm{PH}-$-elicited hepatocyte growth, including TGF- $\alpha$ and HGF and the growth suppressor TGF- $\beta$ (14), were also unaffected by the loss of Gadd $45 \beta$ (Figure 2, E-G). We concluded that the defective proliferation of Gadd $45 b^{-/}$hepatocytes was unlikely due to a perturbation of cytokines or hepatocyte mitogens governing cell-cycle entry/progression after PH and was owing instead to an inability of these cells to successfully enter and/or complete the cell cycle.

To understand the basis for this defective response of Gadd $45 b^{-/-}$ hepatocytes, we examined the expression of cyclins $(14,15,24)$. Remarkably, cyclin D1 (overriding the $\mathrm{G}_{1} / \mathrm{S}$ checkpoint) was upregulated normally in Gadd $45 b^{-/-}$mice, up to 48 hours - its levels being even slightly higher than those in controls at 24 hours - but 
A

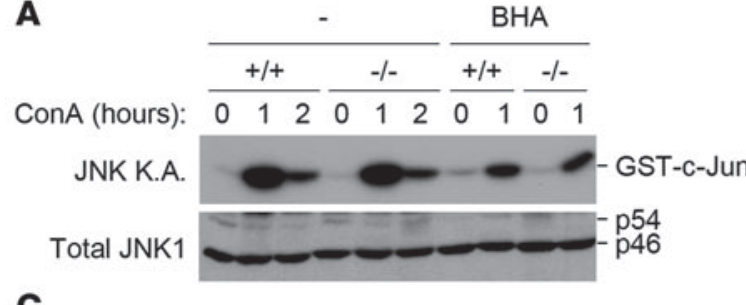

C

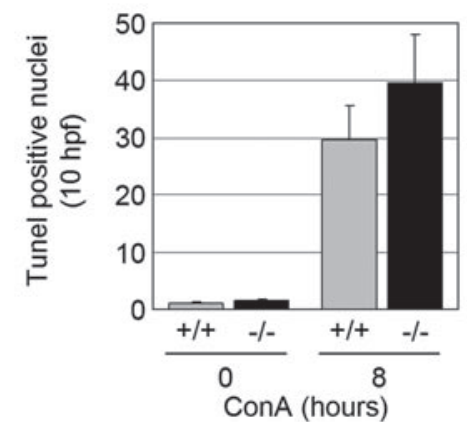

E

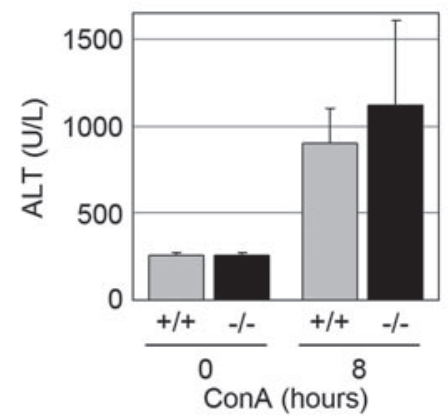

B

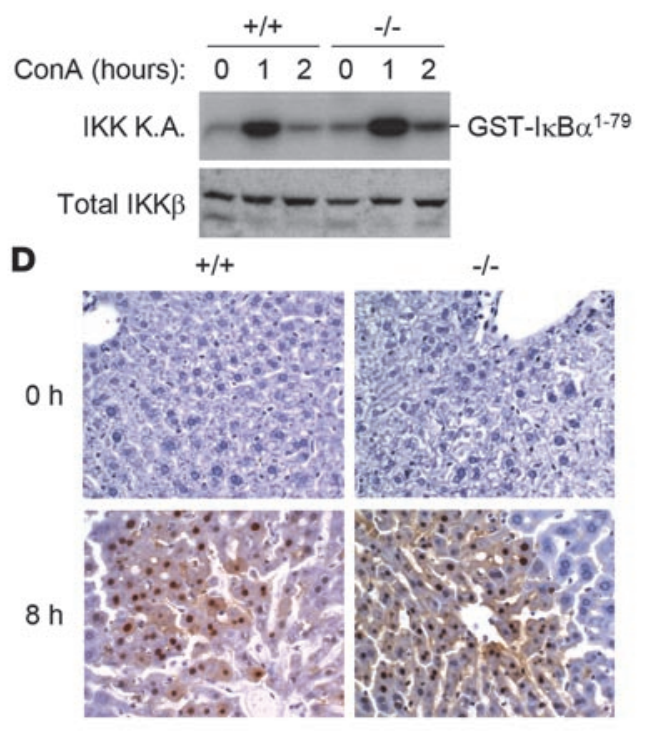

$\mathbf{F}$

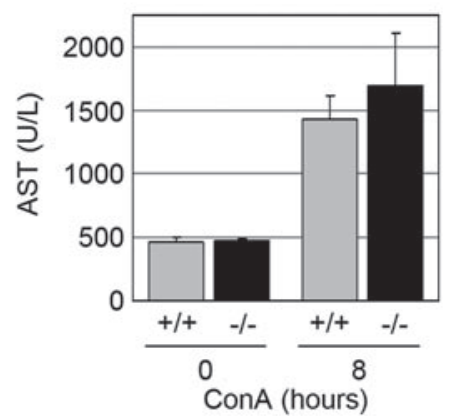

Figure 6

Normal susceptibility of Gadd45 $b^{-/-}$mice to ConA-induced hepatotoxicity. (A) Kinase assays showing JNK activation in livers of Gadd45 $b^{+/+}$and Gadd $45 \mathrm{~b}^{-/-}$mice at the indicates times after ConA injection $(25 \mathrm{mg} / \mathrm{kg})$, in the presence or absence (-) of BHA treatment. Total JNK is shown (Western blots). (B) Kinase assay showing IKK activity in livers of Gadd45 $b^{+/+}$and Gadd $45 b^{-/-}$mice treated with ConA as in A. Total IKK $\beta$ is shown (Western blots). (C) Histomorphometric quantification of TUNEL+ nuclei in livers of Gadd $45 b^{+/+}$and Gadd $45 b^{-/-}$mice $(n=4) 8$ hours after injection of saline (0 hours) or ConA ( 8 hours; $25 \mathrm{mg} / \mathrm{kg}$ ). Values are mean \pm SEM. (D) Images of TUNEL-stained liver sections from representative mice shown in C. Original magnification, $\times 40$. ALT $(\mathbf{E})$ and AST $(\mathbf{F})$ activities in sera of Gadd $45 b^{+/+}$and Gadd $45 b^{-/-}$mice $(n=4) 8$ hours after injection of saline ( 0 hours) or ConA ( 8 hours; $25 \mathrm{mg} / \mathrm{kg}$ ). Values are mean \pm SEM.

then sharply declined by 72 hours (Figure $2 \mathrm{H}$ ). A similar induction profile was observed with cyclin $\mathrm{E} 1$ (also controlling the $\mathrm{G}_{1} / \mathrm{S}$ transition). Conversely, PCNA expression (promoting S-phase progression) was modestly but consistently reduced in Gadd $45 b^{-/}$mice, compared with controls, beginning at 36 hours (Figure $2 \mathrm{H}$ ). In further agreement with the BrdU data (Figure 2, A and B), loss of Gadd45 $\beta$ also markedly impaired upregulation of cyclin A and Cdc2, especially at late times, and virtually abrogated that of cyclin B1 (each controlling the $\mathrm{G}_{2} / \mathrm{M}$ transition) (Figure $2 \mathrm{H}$ ). We concluded that Gadd45b-/hepatocytes successfully commit to cell division and progress to late $\mathrm{G}_{1}$ in response to $\mathrm{PH}$ - unequivocally shown by the normal induction of cyclin D1 (and E1) early on in this response (15) - but then fail to efficiently progress through $\mathrm{S}$ phase and subsequent mitosis (24) (Figure 2, A and B, and Figure 1, B-K and N, respectively).

Extensive PCD in livers of hepatectomized Gadd45 $b^{-1-}$ mice. Thus, we sought to determine whether impaired hepatocyte proliferation in Gadd $45 b^{-/-}$mice was associated with an induction of PCD. Strikingly, livers of Gadd $45 b^{-/-}$mice displayed a high frequency of apoptotic cells 48 hours after $\mathrm{PH}$, whereas wild-type livers contained only few such cells at this time (Figure 3, A and B). Transmission electron microscopy (TEM) also confirmed the presence in Gadd $45 b^{-/-}$livers of necrotic cells - rarely seen in wild-type controls (Figure 3, C-F; see also Figure 1, B-K and L). Together, these data establish an inverse correlation between cell proliferation and both necrosis and apoptosis in regenerating livers from the 2 groups of mice.

To gain further insights into the basis for this hepatoprotective activity of Gadd $45 \beta$, we monitored caspase activation (1). As shown in Figure 3G, Gadd45 $b^{-/-}$livers displayed vigorous processing of procaspase-3, beginning 24 hours after $\mathrm{PH}$, evident from the accumulation of the active cleavage products p17 and p19 (1). This coincided with the appearance of proteolytic fragments from the caspase- 3 substrate poly(ADP) ribose polymerase-1 (PARP-1), an unequivocal sign of caspase activation (Figure $3 \mathrm{G}$ ). These events were specific, since control proteins such as $\beta$-actin and c-FLIP $P_{L}$ were not degraded in the liver extracts (Figure 3G). Remarkably, these $\mathrm{PH}$-triggered events were suppressed by Gadd $45 \beta$ upregulation 
A

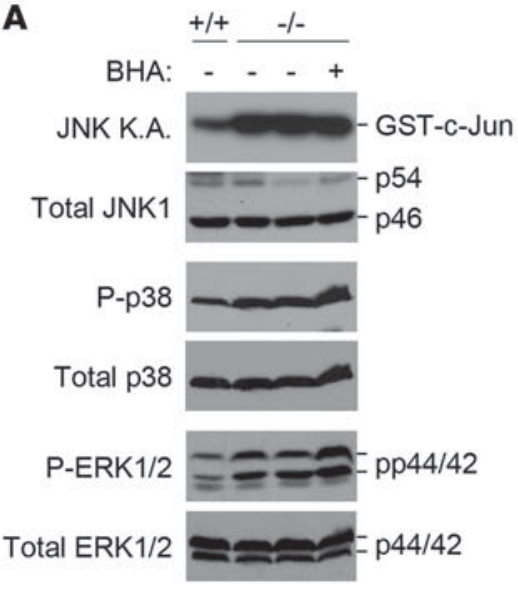

$\mathbf{B}$

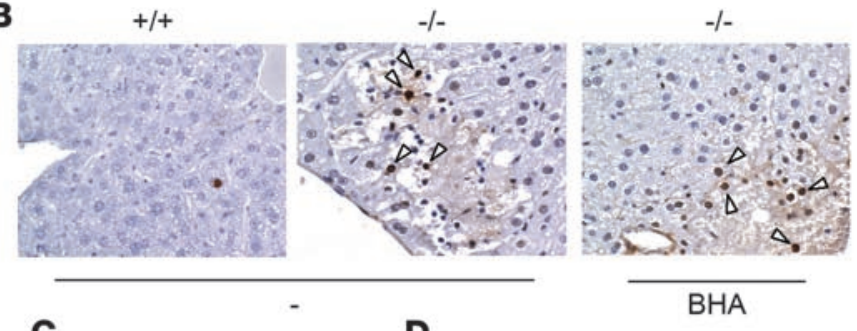

C

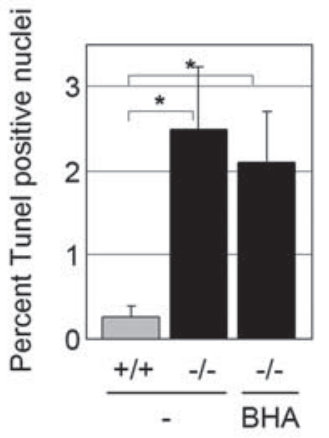

D

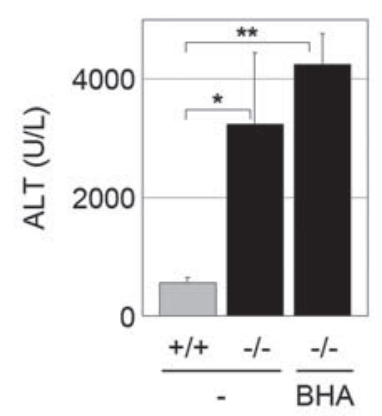

E

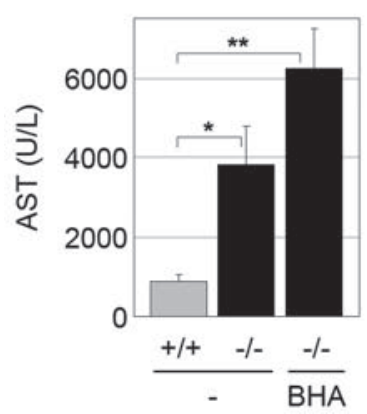

$\mathbf{F}$

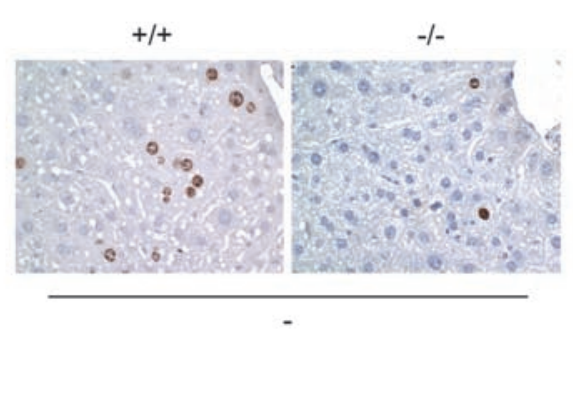

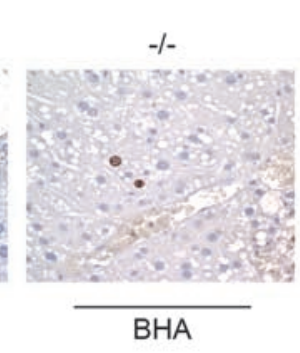

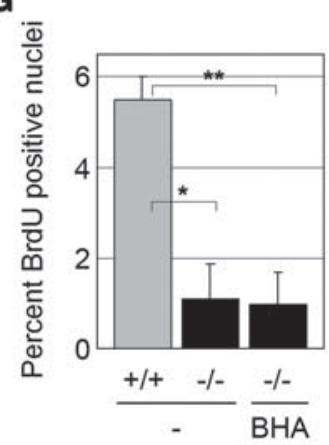

Figure 7

ROSs are not involved in PH-induced, JNK overactivation in Gadd45b-/- mice. (A) Kinase assays and Western blots with antibodies against phosphorylated or total kinases showing MAPK activation in livers of Gadd45 $b^{+/+}$and Gadd $45 b^{-/-}$mice 48 hours after $\mathrm{PH}$, in the presence or absence of BHA treatment. Each lane represents a different mouse. (B) Images of liver sections depicting representative clusters of TUNEL ${ }^{+}$cells from the mice shown in $\mathbf{C}$. Original magnification, $\times 40$. White arrowheads, TUNEL+ hepatocytes with evident chromatin condensation. (C) Histomorphometric quantification of TUNEL + nuclei in livers of Gadd $45 b^{+/+}(n=3)$ and normally $(-; n=6)$ or BHA-fed $(n=6)$ Gadd $45 b^{-/-}$mice 48 hours after PH. Values are mean \pm SEM. ${ }^{*} P<0.05$. ALT (D) and AST (E) activities in sera of Gadd $45 b^{+/+}(n=3)$ and normally $(-; n=6)$ or BHA-fed $(n=6)$ Gadd $45 b^{-/-}$mice 48 hours after $\mathrm{PH}$. Values are mean \pm SEM. ${ }^{\star} P<0.05$, ${ }^{\star \star} P<0.01$. (F) Images of liver sections depicting representative clusters of $\mathrm{BrdU}^{+}$cells from the mice shown in $\mathbf{G}$. Original magnification, $\times 40$. (G) Histomorphometric quantification of BrdU+ nuclei in livers of Gadd45b+/+ $(n=3)$ and normally $(-; n=6)$ or BHA-fed $(n=6)$ Gadd $45 b^{-/-}$mice 48 hours after PH. Values are mean \pm SEM. ${ }^{*} P<0.05$, ${ }^{* *} P<0.01$.

(Figure 3G). Indeed, in wild-type livers, caspase-3 and PARP-1 proforms remained largely intact throughout the time course examined, modest accumulation of their products only being seen at late times and in a limited number of animals. Hence, Gadd $45 \beta$ upregulation during liver regeneration is essential for suppression of both necrosis and apoptosis and enhancement of hepatocyte growth. The finding that the onset of PCD (detectable as early as 24 hours; Figure 3G) preceded that of cell-cycle dysfunction, however, suggests that the proliferation failure observed in livers of Gadd $45 b^{-1-}$ mice is a secondary consequence of the induction of PCD.

Gadd $45 \beta$ controls JNK activation in response to $P H$. The protective activity of Gadd $45 \beta$ in vitro was previously linked to a control of JNK signaling $(5,19)$. Thus, we sought to determine whether the defective regenerative response of $\mathrm{Gadd} 45 \mathrm{~b}^{-/-}$mice was associated with a perturbation of $\mathrm{PH}$-elicited JNK activity. As expected, in wild-type livers, JNK was activated rapidly but weakly after $\mathrm{PH}$, peaking at $1-2$ hours and subsiding by 8 hours (Figure $4 \mathrm{~A}$ ). In contrast, in $\mathrm{Gadd} 45 b^{-/-}$livers, this activation was both vigorous and sustained, high activity being observed at all times examined (Figure 4A; see also Supplemental Figure 3). These findings were confirmed by the use of phospho-specific anti-JNK antibodies, establishing an overactivation in these livers of both JNK1 and JNK2 (predominantly present as p46 and p54 isoforms, respectively) (Figure 4A). Similar results were obtained with the analysis of the MAPK kinase (MAPKK) MAPK kinase 7/JNK kinase 2 (MKK7/JNKK2) (Figure 4A and Supplemental Figure 3), a direct target of Gadd $45 \beta$ in the JNK cascade (19). This Gadd $45 \beta$ afforded suppression of MKK7/JNK signaling was specific, since Gadd $45 \beta$ ablation had no effect on either the p38 or ERK pathways, a slight increase in ERK activity being noted in only a few Gadd45 $b^{-/-}$mice at 8 hours (Figure 4A, Supplemental Figure 3, and data not shown). Gadd $45 \beta$ expression also had no effect on 
PH-elicited NF- $\kappa$ B induction - as shown by IKK kinase assays (Supplemental Figure 4). Hence, Gadd45 $\beta$ upregulation selectively suppresses JNK activation early on after PH.

Notably, in hepatectomized Gadd45 $b^{-/-}$mice, MKK7 and JNK activities were markedly elevated even at later times (i.e., 24 hours and thereafter), coincident with a second phase of MAPK activation. During this phase, the difference between Gadd45 $b^{-/-}$and control mice became most evident in kinase assays by 36 hours, persisting to at least 72 hours (Figure 4B; see also Supplemental Figure 5). Again, this difference was confirmed by the use of phospho-specific anti-JNK antibodies, showing a marked activation of JNK1 and JNK2 in Gadd45 $b^{-/-}$mice, beginning at 24 hours, but not in control mice (Figure 4B; see also Figure 5G). As seen at earlier times (Figure $4 \mathrm{~A}$ ), these effects of Gadd $45 \beta$ were specific, as ERK and p38 phosphorylation was essentially comparable in the 2 genotypes (Figure 4B), although a slight elevation in this phosphorylation was noted in some $\mathrm{Gadd} 45 \mathrm{~b}^{-/-}$mice at 48 hours (Supplemental Figure 5). At these later times, however, ERK and p38 activities displayed some degree of variability in both groups of mice (Supplemental Figure 5). Indeed, the effects of Gadd $45 \beta$ on these activities are in stark contrast to the magnitude and consistency of those on the JNK cascade, suggesting that the former effects are only an indirect consequence of Gadd $45 \beta$ expression, possibly owing to caspase activation in mutant mice (Figure $3 \mathrm{G}$ ) (1). This magnitude and consistency, especially early on after $\mathrm{PH}$, in fact suggest that JNK overactivation may be a cause for the impaired regenerative response of Gadd $45 b^{-1-}$ mice.

Loss of JNK2 restores normal liver regeneration in Gadd456-/- mice. To test this hypothesis, we examined whether inhibition of JNK rescued liver regeneration in Gadd45 $b^{-/-}$mice. To this end, we generated Gadd $45 b^{-/-}$mice harboring a JNK2-null mutation, which, like JNK1 mutation, blunts hepatotoxic JNK signaling but, in contrast to this mutation, has no adverse effect on c-Jun phosphorylation or cytokine expression during TNFR-mediated hepatic challenge $(12,25)$ - events that are both required for liver regeneration $(14,18)$. As expected, loss of Gadd $45 \beta$ markedly increased serum transaminase activities 48 hours after PH (Figure 5, A and B; compare -/- and +/+; see also Figure 1, P and Q). Remarkably, however, the compound mutation of JNK2 restored these activities in Gadd45 $b^{-1-}$ mice to wild-type levels (Figure 5, A and B, double KO [dKO]). Indeed, knocking out JNK2 completely rescued Gadd45b-/hepatocytes from $\mathrm{PH}$-induced apoptosis, as shown by the comparably low numbers of TUNEL ${ }^{+}$cells observed in $\mathrm{dKO}$ and wild-type livers at 48 hours - in contrast, these numbers were expectedly high in Gadd45b-/- livers (Figure 5, C and D; see also Figure 3, A and B). Strikingly, JNK2 deletion also restored Gadd45b $b^{-1}$ hepatocyte proliferation in response to $\mathrm{PH}$ : no differences were noted between $\mathrm{dKO}$ and wild-type livers in frequencies of $\mathrm{BrdU}^{+}$cells, while only few such cells were detected in Gadd45 $b^{-/-}$livers (Figure 5, E and F; see also Figure 2, A and B). Hence, JNK2 ablation fully corrects the impaired regenerative response of $\mathrm{Gadd}_{4} 5 \mathrm{~b}^{-/-}$mice, restoring both hepatocyte survival and proliferation.

Significantly, JNK1/2 overactivation in hepatectomized Gadd45 $b^{-/-}$ mice did not appreciably enhance c-Jun phosphorylation (Figure 4, A and B; see also Figure 5G), and this phosphorylation (as well as c-Jun expression) was further unaffected by the compound deletion of JNK2 (Figure 5G, dKO). Similar findings were obtained when this deletion was analyzed in mice on a wild-type background (12). JNK2 ablation in Gadd45 $b^{-/-}$mice also caused no further compensatory increase in JNK1 activation after $\mathrm{PH}$, thereby confirming that it yielded an overall reduction in total JNK activity (Figure 5G; compare phospho-p46 in Gadd45b-/- and dKO mice; also note the reduced cumulative $\mathrm{p} 46 / \mathrm{p} 54$ phosphorylation present in $\mathrm{dKO}$ mice relative to Gadd45 $b^{-/-}$mice). Hence, judging from c-Jun phosphorylation, neither Gadd $45 \beta$ ablation nor compound JNK2 mutation - enhancing and blunting overall JNK activity, respectively - appeared to directly affect PH-elicited hepatocyte proliferation. Rather, it appeared to be the suppression of JNK-inflicted PCD that accounted for the corrective effects of JNK2 ablation on Gadd45 $b^{-1-}$ hepatocyte proliferation (see Discussion). Irrespective of the basis for these effects, the above data causally link Gadd $45 \beta$ function in liver regeneration to a control of the JNK cascade.

Normal response of Gadd $45 b^{-/-}$mice to ConA challenge. Thus, we investigated whether Gadd $45 \beta$ is a general hepatic modulator of TNFRinduced JNK signaling. To this end, we examined the response of Gadd $45 b^{-/-}$mice to ConA injection, which also upregulates hepatic Gadd45b expression (Supplemental Figure 6A) and triggers hepatic injury through TNFR-elicited JNK activity $(7,8)$. As shown in Figure 6A, ConA caused potent JNK activation in both Gadd45 $\mathrm{b}^{-/-}$and Gadd $45 b^{+/+}$livers - the magnitude and duration of this activation being unaffected by Gadd $45 \beta$ expression. ConA-elicited NF-кB activity - countering JNK-inflicted hepatotoxicity caused by this agent (11) - was also unaffected by Gadd45b status (Figure 6B). In line with this normal induction of NF- $\mathrm{KB}$ and JNK activities, Gadd $45 b^{-/-}$mice displayed no increased susceptibility to ConAinduced hepatic damage, as compared with controls - shown by an assessment of mortality rates (data not shown), frequencies of apoptotic cells (Figure 6, C and D), and serum transaminase levels (Figure 6, E and F) in the 2 groups of animals (see also Supplemental Figure 6, B-E; $10 \mathrm{mg} / \mathrm{kg}$ ConA). Similar conclusions were drawn from experiments involving LPS/GalN challenge (data not shown), which also induces hepatic Gadd45b expression (Supplemental Figure 2C) and inflicts hepatotoxicity through a TNFR1dependent, JNK-mediated mechanism $(7,11)$.

To verify that the apparent failure of Gadd $45 \beta$ to counter ConAinduced hepatic injury was not due to an abnormal synthesis in Gadd $45 b^{-/-}$mice of cytokines mediating this injury (11), we monitored TNF- $\alpha$ levels. As shown in Supplemental Figure 6, A and F, however, these levels rose comparably after ConA injection within the liver tissue and sera of Gadd45 $b^{-/-}$and control mice. ConAinduced IL-6 expression, a functional readout of TNFR activity (16), was similarly unperturbed by the loss of Gadd $45 \beta$ (Supplemental Figure 6, A and G). We concluded that Gadd45 $\beta$ is either dispensable or functionally redundant for antagonism of ConAand LPS-induced hepatotoxic JNK signaling and that NF-кBinducible effectors other than Gadd $45 \beta$ are primary mediators of this antagonism in the hepatic tissue (see Discussion).

ROS-independent JNKoveractivation in hepatectomized Gadd456 $b^{-/}$mice. How this specificity in the mechanism for JNK restraint is achieved in the liver is unknown. We reasoned, however, that this might be influenced by differences in the TNFR-induced pathway(s) for JNK activation elicited by distinct stimuli. It was shown in fact that ConA-induced JNK signaling and hepatotoxicity depend on an elevation of ROS and that this elevation is not involved in the transient induction of JNK normally elicited by $\mathrm{PH}(7,13)$. Consistently, antioxidant treatment with butylated hydroxyanisole (BHA) effectively attenuated ConA-induced JNK activation in both wild-type and Gadd456 $b^{-/-}$mice (Figure 6A). Thus, we examined whether ROS also participated in the exacerbated induction of JNK observed during liver regeneration in Gadd $45 b^{-/-}$mice. Remarkably, however, in con- 
trast to what was seen with ConA (Figure 6A), JNK overactivation by $\mathrm{PH}$ in these mice was unaffected by BHA treatment (Figure 7A), indicating that it was independent of ROS. Antioxidant treatment also failed to attenuate $\mathrm{PH}$-elicited p38 signaling, whereas it caused a slight increase in ERK activity in some animals (Figure 7A).

Consistent with this inability to prevent JNK overactivation, ROS attenuation afforded no protection in Gadd45 $b^{-/-}$mice against PHelicited hepatotoxicity, as shown by TUNEL assays (Figure 7, B and C) and analysis of serum transaminase levels (Figure 7, D and E). It also failed to enhance Gadd45b $b^{-/-}$hepatocyte proliferation in response to $\mathrm{PH}$ (Figure 7, F and G; compare numbers of $\mathrm{BrdU}^{+}$ hepatocytes in BHA-treated and untreated mutant mice). Hence, $\mathrm{PH}$-elicited JNK overactivation and hepatic injury in Gadd45 $b^{-/-}$ mice are both independent of ROS.

These data are in stark contrast to the ability of JNK attenuation to restore a normal regenerative response in these mice and underscore the fundamental differences in the mechanism(s) governing TNFR-induced, sustained JNK signaling and hepatotoxicity during $\mathrm{PH}$ and ConA challenge. Further, they indicate that Gadd $45 \beta$ is an essential component of the inducible hepatic program for control of this signaling during liver regeneration, when this signaling is independent of ROS; but that it is dispensable for this control during ConA challenge, when sustained JNK signaling is elicited through an elevation of $\operatorname{ROS}(7,13)$. Hence, the protective hepatic response to TNFR-mediated challenge appears to be tailored to optimally respond to the specific challenge (see Discussion).

\section{Discussion}

We show that Gadd $45 \beta$ upregulation by PH depends on TNFR1 (Supplemental Figure 2B) and that this upregulation is required for liver regeneration. Loss of Gadd $45 \beta$ profoundly impairs hepatocyte survival and proliferation in response to $\mathrm{PH}$ (Figures 1-3). The abortive regenerative response of $\mathrm{Gadd} 45 \mathrm{~b}^{-/-}$mice is associated with selective overactivation of the MKK7/JNK pathway (Figure 4 and Supplemental Figures 3-5), and inhibition of this pathway by JNK2 ablation fully corrects this response (Figure 5). These data establish a central role for JNK signaling in control of cell fate during liver regeneration and causally link the function of Gadd $45 \beta$ in this process to a regulation of this signaling. Notably, Gadd45 $\beta$ upregulation has no effect on TNFR-induced JNK activation and hepatic injury during ConA (or LPS) challenge (Figure 6 and data not shown), which also inflicts this injury through a sustained activation of JNK (7). Hence, the inducible hepatic program for JNK restraint during TNFR-mediated challenge exhibits a high degree of contextual specificity, and there seems to be an intimate link between this program and the TNFR-induced pathway for JNK activation elicited by a specific challenge.

Roles of Gadd $45 \beta$ in liver regeneration. Liver regeneration after loss of liver tissue is a fundamental paradigm of the hepatic response to challenge $(14,16)$. This process involves complex changes in liver physiology and is initially orchestrated by the coordinated induction of a program of immediate-early genes $(15,16)$. Gadd45b has consistently emerged in genome-wide screens as one those exhibiting the strongest upregulation after $\mathrm{PH}(20,21)$, and we show here that this upregulation is essential for liver regeneration. Our data are consistent with a model whereby the triggering of TNFR1, early on after PH, causes activation of NF- $\mathrm{KB}$, leading to Gadd $45 \beta$ induction, which then prevents sustained JNK activation by the targeting of MKK7, ultimately enabling hepatocyte survival and proliferation. Indeed, targeted disruption of Gadd $45 b$ selec- tively impairs downregulation of PH-elicited MKK7/JNK signaling (Figure 4 and Supplemental Figures 3-5), and attenuation of this signaling by compound JNK2 deletion normalizes the abortive regenerative response of Gadd45 $b^{-/-}$mice (Figure 5). These data identify the control of the JNK cascade as a primary mechanism for Gadd $45 \beta$ function during liver regeneration (discussed below).

Induction of NF- $\mathrm{\kappa B}$ and Gadd $45 \beta$ during liver regeneration critically depends on TNFR1 (ref. 15; see also Supplemental Figure $2 \mathrm{~B})$, which governs hepatocyte priming $(15,26)$. Whereas the role of NF-кB in TNFR1-elicited Gadd45b upregulation during liver regeneration remains to be confirmed, available evidence strongly supports such a role. Gadd45b is a known target of NF- $\mathrm{KB}$, and in various systems, including hepatic systems, its induction by TNF- $\alpha$

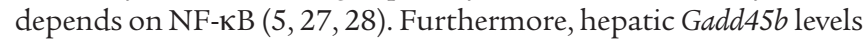
are markedly induced by both LPS and ConA challenges (Supplemental Figure 2C and Supplemental Figure 6A), which activate NF- $\mathrm{KB}$ within hepatocytes $(7,11,28)$, and in the inflamed liver tissue, elevated Gadd $45 \beta$ expression is abolished by the injection of anti-TNF- $\alpha$ antibodies or expression of inhibitor of $\kappa B \alpha$ mutant $(\mathrm{I} \kappa \mathrm{B} \alpha \mathrm{M})(27)$. These data establish a link among the hepatic activities of TNFR1, NF- $\kappa B$, and Gadd $45 \beta$ and suggest that the TNFR1afforded control of liver regeneration is exercised, at least in part, through NF-KB-dependent upregulation of Gadd45b.

The role of NF-кB in this process, however, remains controversial. Whereas initial studies using adenoviral I $\mathrm{\kappa} \beta \mathrm{M}$ delivery

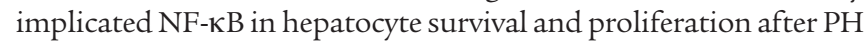
(29), subsequent studies showed that hepatocyte-specific IкB $\alpha \mathrm{M}$ expression has no adverse effect on these processes (10). This led to the conclusion that NF- $\mathrm{KB}$ exerts its role in liver regeneration primarily within nonparenchymal cells (NPCs), where it promotes the synthesis of factors that stimulate hepatocyte growth $(7,10$, 14). Yet NF- $\kappa B$ blockade in the latter animal model was partial $(10,28)$, so whether NF-кB plays additional, cell-intrinsic role(s) within hepatocytes remains to be determined. Support for these roles, however, comes from other models of compensatory hepatocyte growth, which showed that NF- $\mathrm{KB}$ activation in these cells induces protective genes that counter TNF- $\alpha$-inflicted PCD $(4,7$, $30,31)$. Thus, NF-кB likely plays important roles in liver regeneration within both hepatocytes and NPCs.

Conversely, our data track the $\operatorname{defect}(\mathrm{s})$ of $\mathrm{Gadd} 45 \mathrm{~b}^{-/-}$mice in this process primarily to hepatocytes. Gadd $45 \beta$ ablation caused no apparent perturbation of $\mathrm{PH}$-elicited synthesis of growth-promoting cytokines produced by NPCs, including TNF- $\alpha$, IL- 6 , and HGF (Figure 2) $(14,16)$. Gadd45 $b^{-1-}$ mice also exhibited normal cytokine induction in response to ConA (Supplemental Figure 6), consistent with the view that they display an essentially intact NPC compartment.

Roles of Gadd $45 \beta$ in control of JNK signaling during liver regeneration. We show that the hepatocyte fate during liver regeneration is decided early on after $\mathrm{PH}$ and that this decision is critically governed, at least in part, by the intensity and duration of JNK activation. The role of JNK in hepatotoxicity and that of a program for its restraint in hepatoprotection were previously established in the ConA, LPS, and TNF- $\alpha$ models of liver challenge $(7,8)$. These roles, however, had not been previously recognized during liver regeneration, as the effects of JNK inhibition during this process were mainly investigated under conditions of transient JNK activity.

We also identify Gadd $45 \beta$ as a key inducible modulator of JNK signaling (Figure 4 and Supplemental Figures 3 and 5), and hence of hepatic cell fate (Figures 1-3 and 5), during liver regeneration. Indeed, by controlling the duration and intensity of this signal- 
ing, Gadd45b upregulation by TNFR1 acts as a switch that converts an otherwise hepatotoxic response to one of proliferation. This Gadd $45 \beta$-afforded control of JNK activity is specific, as in hepatectomized Gadd45 $b^{-/-}$mice, deregulation of p38 and ERK activities was only seen in some animals and at late times (Figure 4 and Supplemental Figures 3 and 5). Moreover, impaired liver regeneration in these mice was fully corrected by the introduction of a Jnk2-null allele (Figure 5). These findings are consistent with previous in vitro data that identified Gadd $45 \beta$ as a specific inhibitor of TNFR1-induced JNK signaling and a putative mediator of the NF-KB-afforded control of this signaling $(2,5)$. Thus, it is plausible that the Gadd $45 \beta$-directed targeting of MKK7 mediates NF- $\kappa \mathrm{B}-J N K$ crosstalk during liver regeneration (see below).

Of note, it appears to be an overall reduction in total JNK activity, rather than a qualitative change in this activity, that accounts for the corrective effects of JNK2 ablation in Gadd45 $b^{-/-}$mice (Figure 5). Indeed, while there is controversy over whether the hepatic JNK isoforms JNK1 and JNK2 have specialized functions in cell growth and PCD, knockout studies have shown that both contribute to TNFR-mediated hepatic injury in animal models displaying JNK overactivation $(8,9,11,12)$. Other studies using chemical genetic or $\mathrm{dKO}$ model systems further underscore the virtually overlapping roles of these isoforms in c-Jun phosphorylation, cell proliferation, and PCD $(32,33)$.

Interestingly, in contrast to their relevance to PCD induction, intensity and duration of JNK activation appear to have relatively little influence on JNK participation in hepatocyte proliferation. Indeed, whereas Gadd45 $b^{-/-}$mice display overactivation of both JNK1 and JNK2 after $\mathrm{PH}$, this overactivation does not translate into an increased phosphorylation of c-Jun (Figure 4, A and B, and Figure $5 \mathrm{G}$ ). This is further unaffected by the compound mutation of JNK2 (Figure 5G). Thus, judging from c-Jun expression and phosphorylation, neither Gadd $45 \beta$ ablation nor compound JNK2 mutation - promoting and blunting JNK overactivation, respectively - significantly impacts JNK-dependent hepatocyte growth after $\mathrm{PH}(17,18)$, suggesting that the effects of Gadd $45 \beta$ on liver regeneration are primarily exerted through a control of PCD.

Also in line with this view, early on after $\mathrm{PH}$, livers of Gadd45 $\mathrm{b}^{-/-}$ mice display normal cyclin D1 induction (Figure $2 \mathrm{H}$ ), which marks the point during liver regeneration at which control is typically exercised and hepatocytes become irreversibly committed to cell division and independent of mitogens for growth $(14,15,34)$. These findings and the relatively late onset of cyclin perturbations in Gadd45 $b^{-1-}$ mice are consistent with a model whereby impaired hepatocyte proliferation in these mice is a secondary consequence of PCD induction, and this in turn is a consequence of JNK overactivation.

Specificity of the hepatic mechanism for control of JNK signaling during TNFR-mediated challenge. Interestingly, Gadd $45 \beta$ upregulation critically affects the liver response to PH (Figures 1-3) but has no effect on the liver response to ConA (or LPS) exposure (Figure 6, Supplemental Figure 6, and data not shown), despite the fact that each of these responses is chiefly governed by the kinetics of TNFR-induced JNK activation $(7,8)$. The basis for this contextual specificity of the Gadd $45 \beta$ hepatic function is unknown. It is possible, however, that this is dictated in part by intrinsic differences in the strength and/or quality of the TNFR-induced signal(s) for JNK activation triggered by a specific challenge. It is noteworthy in this regard that ConA usually elicits a more vigorous JNK activation than $\mathrm{PH}$, which may depend in part on its ability to promote ROS formation downstream of TNFRs $(2,7,13)$. Accordingly, anti- oxidant treatment effectively blunts ConA-induced JNK overactivation and hepatic injury in mice (refs. 7, 13, and Figure 6A).

Yet this treatment has no effect on JNK activation or liver regeneration after PH (ref. 13; see also Figure 7). This inefficacy of antioxidants to counter these processes is believed to depend on the transient nature of the JNK induction response usually elicited by $\mathrm{PH}$ (13), a response that, unlike the sustained JNK induction response, is normally independent of $\operatorname{ROS}(2,13,35)$. Remarkably, however, in hepatectomized Gadd45 $b^{-/-}$mice, sustained JNK activation was insensitive to ROS inhibition (Figure 7). Hence, contrary to what is generally thought, ROSs are not obligatory mediators of exaggerated, TNFR-induced JNK signaling. Rather, this signaling can be elicited through both ROS-dependent and -independent pathways, depending on the biological context. Indeed, it is plausible that JNK overactivation in Gadd45 $b^{-/-}$mice results from unrestrained activity of MKK7, a ROS-insensitive MAPKK (2).

Notably, irrespective of the challenge, the inducible hepatic program for JNK attenuation appears to be chiefly orchestrated

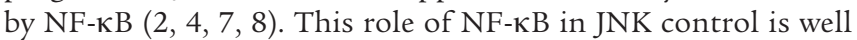
established during ConA, LPS, and TNF- $\alpha$ challenge $(7,8)$, and we show here that this control during liver regeneration involves the upregulation of Gadd45b - a target of NF- $\mathrm{\kappa B}$ (5). In addition to direct inhibitors of the JNK cascade such as Gadd $45 \beta$, putative effectors of NF-KB-JNK crosstalk include antioxidant factors such as manganese-superoxide dismutase (Mn-SOD) and ferritin heavy chain (FHC) $(2,13,35)$. Accordingly, the NF-кB-activated hepatic mechanism for JNK restraint may be tailored to optimally respond to the specific challenge, primarily relying on Gadd $45 \beta$-like factors during liver regeneration, a process in which sustained JNK activation is independent of ROS (ref. 13; Figure 7), and on antioxidants instead during ConA challenge, in which this activation is induced through an elevation of $\operatorname{ROS}(7,13)$. Regardless of the basis for this selectivity of the hepatic action of Gadd $45 \beta$, our data identify this factor as a crucial modulator of TNFR-induced JNK signaling during liver regeneration and provide a paradigm for the inducible control of this signaling, and hence of cell fate, in vivo.

Defects in hepatocyte PCD and/or compensatory growth are key pathogenetic elements in widespread liver conditions such as hepatitis, toxic and ischemia-reperfusion injuries, and hepatocellular carcinoma $(16,28)$. Often associated with these conditions are disturbances of the NF- $\kappa \mathrm{B}-\mathrm{JNK}$ response to TNF- $\alpha$-induced signals (28). Accordingly, drugs targeting the NF- $\mathrm{KB}$ and JNK pathways are being considered for treatment of these pathologies (28). Due to the ubiquitous nature of these pathways, however, these drugs have broad, multiorgan side effects (28) that limit their clinical use. The discovery of specificity in the inducible hepatic mechanism for JNK control has therefore profound implications for developing new tools for modulation of NF-KB-JNK crosstalk in specific pathophysiological contexts. The Gadd45 $\beta$-MKK7 interaction may in fact provide a suitable molecular target for devising such tools.

\section{Methods}

Animals. Information on the generation of Gadd $45 b^{-/-}$mice can be found in Supplemental Data. Jnk2-/- mice were provided by C.-Y. Kuan (Cincinnati Children's Hospital Medical Center, Cincinnati, Ohio, USA) and R. Flavell (Yale University School of Medicine, New Haven, Connecticut, USA) (36) and

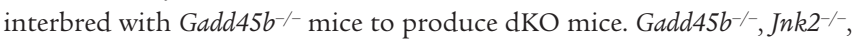
and $\mathrm{dKO}$ mice were on a mixed C57BL/ $6 \times 129 \mathrm{SV}$ background, and experiments were controlled using littermates. C57BL/6 and Tnfrsf1 $a^{-/-}(\mathrm{C} 57 \mathrm{BL} / 6)$ mice were from the Jackson Laboratory. Mice were maintained in approved 
facilities at the University of Chicago, fed with irradiated 5\% fat chow (2918; Harlan) ad libitum, and handled according to NIH guidelines under a protocol approved by the University of Chicago IACUC. Where indicated, mice were fed on a BHA-rich diet (0.75\% BHA-custom Harlan 2918), starting 48 hours prior to ConA or $\mathrm{PH}$ challenge.

Animal procedures. Seventy percent $\mathrm{PH}$ was performed as described previously (37), using 12- to 21 -week-old males. Briefly, mice were anesthetized with ketamine and xylazine $(100 \mathrm{mg} / \mathrm{kg} / 10 \mathrm{mg} / \mathrm{kg}$; i.p.). The liver was exposed through a midline incision, and the median and left lobes were mobilized and delivered after ligature with a single silk 4-0 suture. ConA (Sigma-Aldrich) was injected i.v. at the indicated doses in $0.9 \% \mathrm{NaCl}$. LPS (E. coli O127:B8; Sigma-Aldrich) was administered i.p. at $35 \mathrm{mg} / \mathrm{kg}$ in PBS. Blood was collected by retro-orbital puncture, following IACUC-approved procedures. Animals were sacrificed with $\mathrm{CO}_{2}$ followed by cervical dislocation, and tissues were removed and flash-frozen in liquid $\mathrm{N}_{2}$ for biochemical analyses or fixed in $4 \%$ buffered formalin for histology.

Protein, $m R N A$, and DNA analyses. Western blots (WBs) and kinase assays (KAs) were performed as described previously $(5,11,19)$. For protein extraction, liver homogenates were prepared using NP-40 lysis buffer $(20 \mathrm{mM}$ HEPES, pH 8.0; $350 \mathrm{mM} \mathrm{NaCl} ; 20 \%$ glycerol; $1 \% \mathrm{NP}-40 ; 1 \mathrm{mM} \mathrm{MgCl}_{2}$; 0.2 mM EGTA, pH 8.0). Antibodies were as follows: MKK7 (WB and KA), IKK $\gamma$ (KA), IKK $\beta$, cyclin E1, cyclin B1, cyclin A (C-19), PCNA, Cdc2, $\beta$-actin (Santa Cruz Biotechnology Inc.); cyclin D1 (Zymed Laboratories; Invitrogen); HGF $\alpha$ (Assay Designs); c-FLIP (Stressgen); total JNK1 (WB and KA; BD Biosciences); caspase-3, PARP-1, phospho-JNK1/2, phospho-c-Jun, phospho-p38, phospho-ERK1/2, total JNK2, total p38, total ERK1/2, total c-Jun, TGF- $\beta$ (Cell Signaling Technology). Serum transaminase activities were determined by using Reflotron GPT (alanine transaminase) and GOT (aspartate transaminase) tabs and a Reflotron Plus Chemistry Analyzer (Roche Diagnostics), according to the manufacturer's instructions. Concentrations of TNF- $\alpha$ and IL- 6 in sera and liver homogenates were determined by sandwich ELISA using appropriate antibody combinations (ELISA capture; BD Biosciences) and following the manufacturer's recommendations.

For PCR analyses, total RNA was extracted using TRIzol Reagent (Invitrogen), and cDNA was prepared using SuperScript II (Invitrogen) and 1 or $2 \mu \mathrm{g}$ total RNA, as described previously (38). Standard RT-PCR for analysis of Tffa, Tnfa, Il6, Gadd45b, and Actb transcripts was performed as detailed elsewhere (38). For QRT-PCR, Gadd45 family gene expression was measured using a MX3000PTM real-time PCR apparatus (Stratagene), and cDNA (100 ng) was amplified using Brilliant SYBR Green mix (Stratagene), according to the manufacturer's instructions. Results were normalized to hypoxanthine guanine phosphorybosil transferase $(\mathrm{Hrpt})$ levels. Fluorescence was captured at $72^{\circ} \mathrm{C}$. Primer sequences are provided in Supplemental Methods. Southern blots were performed according to standard protocols.

Histological analyses and TEM. For histological analyses, livers were fixed in $4 \%$ buffered formalin, dehydrated, embedded in paraffin, sectioned $(5 \mu \mathrm{m})$, and then processed either for routine H\&E staining or BrdU or TUNEL assays, as described previously (37). For BrdU assays, mice were injected i.p. 2 hours before sacrifice with $\mathrm{BrdU}(100 \mu \mathrm{g} / \mathrm{kg})$. Histopathology grades at $\mathrm{H} \& \mathrm{E}$, and BrdU and TUNEL assays were scored blindly in either 10 or 20 nonoverlapping high-power fields (hpfs; $\times 40$, ConA injections; $\times 20$, all other challenges). Histopathology grades were quantitatively scored in a random order and without knowledge of animal treatment or group identity. Grades were defined as follows: (a) The $\mathrm{CN}$ grade (Figure $1 \mathrm{~L}$ ) was subjectively scored by global assessment of a liver tissue section that comprised an entire crosssection of at least one of the regenerating right liver lobes on a scale of 0 (no focus of $\mathrm{CN}$ ), 0.5 (one focus of $\mathrm{CN}$ ), 1 (greater than 1 focus of $\mathrm{CN}$ in at least two regions, but not diffusely scattered throughout the liver lobe), 2 (diffuse small foci of $\mathrm{CN}$ across an entire liver lobe), and 3 (diffuse and large area of geographic necrosis). (b) The inflammation grade (Figure 1M) was subjectively scored on a scale of 0 (no inflammation), 1 (at least one focus or neutrophil-rich inflammation in at least two low-power [ $x 4$ ] fields), 2 (greater than two foci of neutrophil-rich inflammation in at least two low-power fields), 3 (diffuse and large area of neutrophil-rich inflammation). (c) Steatosis (large or small intracytoplasmic fat droplets) grade (Figure 1O) was subjectively scored as the number of hepatocytes within the hepatic lobule that contained fat droplets on a scale of 0 (no steatosis), 1 (less than one-third of lobule), 2 (one-third to two-thirds of lobule), 3 (panlobular). Hepatocyte mitotic figures (Figure $1 \mathrm{~N}$ ) were counted in 20 nonoverlapping hpfs using a Nikon Eclipse 50i microscope with a $\times 10$ eyepiece and a $\times 20$ objective. Mitotic figures are reported as fractions of the total number of hepatocytes examined (i.e., number of mitoses $/ 100$ hepatocytes; Figure $1 \mathrm{~N}$ ).

TEM was performed as described previously (38). Briefly, freshly isolated liver aliquots were fixed for 2 hours in $4 \%$ paraformaldehyde, $1.25 \%$ glutaraldehyde, $0.1 \mathrm{M}$ sodium cacodylate, followed by secondary fixation with $1 \%$ $\mathrm{OsO}_{4}$ and $0.1 \mathrm{M}$ sodium cacodylate buffer. Fixed tissues were then dehydrated with ethanol, stained using uranyl and lead acetate, and finally embedded in EPON. Sections (50 nm thick) were analyzed using an FEI Tecnai F30ST electron microscope at the University of Chicago Electron Microscopy Facility.

Statistics. Data are reported as mean \pm SEM or SD, as stated. Differences were analyzed by Student's $t$ test (2-tailed, Figures $1-3$ and 5; 1-tailed, Figures 6 and 7), and $P$ values $\leq 0.05$ were considered significant. The log-rank test was used in assessing the significance seen in survival analyses. Unless otherwise stated, $P$ values are from Student's $t$ test.

\section{Acknowledgments}

This work was supported in part by NIH grants CA84040 and CA98583 and Cancer Research UK grant C26587-A8839 to G. Franzoso; grant DK067187 to R.A. Anders; and a grant from the Associazione Italiana per la Ricerca sul Cancro (AIRC) to F. Zazzeroni. S. Papa is supported in part by the PhD Program in Experimental Medicine and Endocrinology, University of L'Aquila. C. Bubici is supported in part by a fellowship from the AmericanItalian Cancer Foundation (AICF). We thank R. Flavell and C.-Y. Kuan for the Jnk2 $2^{-/}$mice; A. Ma for the ES cells and assistance with growth of these cells; L. Degelstein for blastocyst injections; $\mathrm{T}$. Li and X. Jiang for technical assistance with histology staining; and C. Mauro for critical comments on the manuscript.

Received for publication September 13, 2007, and accepted in revised form February 27, 2008.

Address correspondence to: Guido Franzoso, University of Chicago, 924 E 57th Street, BSLC R122, Chicago, Illinois 60637, USA. Phone: (773) 702-4729; Fax: (773) 702-3701; E-mail: gfranzos@ midway.uchicago.edu or g.franzoso@imperial.ac.uk.

Salvatore Papa, Concetta Bubici, and Guido Franzoso's present address is: Department of Immunology, Division of Investigative Science, Imperial College London, London, United Kingdom

Francesca Zazzeroni's present address is: Department of Experimental Medicine, The University of L'Aquila, L'Aquila, Italy.

Robert A. Anders's present address is: Department of Pathology, Johns Hopkins University School of Medicine, Baltimore, Maryland, USA.

Salvatore Papa and Francesca Zazzeroni contributed equally to this work. 
1. Wajant, H., Pfizenmaier, K., and Scheurich, P. 2003. Tumor necrosis factor signaling. Cell Death Differ. 10:45-65.

2. Papa, S., et al. 2006. The NF-кB-mediated control of the JNK cascade in the antagonism of programmed cell death in health and disease. Cell Death Differ. 13:712-729.

3. Basseres, D.S., and Baldwin, A.S. 2006. Nuclear factor- $\kappa \mathrm{B}$ and inhibitor of $\kappa \mathrm{B}$ kinase pathways in oncogenic initiation and progression. Oncogene. 25:6817-6830.

4. Karin, M. 2006. Nuclear factor- $\kappa B$ in cancer development and progression. Nature. 441:431-436.

5. De Smaele, E., et al. 2001 . Induction of gadd $45 \beta$ by NF- $\mathrm{B}$ downregulates proapoptotic JNK signalling. Nature. 414:308-313.

6. Tang, G., et al. 2001. Inhibition of JNK activation through NF-кB target genes. Nature. 414:313-317.

7. Schwabe, R.F., and Brenner, D.A. 2006. Mechanisms of Liver Injury. I. TNF- $\alpha$-induced liver injury: role of IKK, JNK, and ROS pathways. Am. J. Physiol. Gastrointest. Liver Physiol. 290:G583-G589.

8. Wullaert, A., Heyninck, K., and Beyaert, R. 2006. Mechanisms of crosstalk between TNF-induced NF-kappaB and JNK activation in hepatocytes. Biochem. Pharmacol. 72:1090-1101.

9. Chang, L., et al. 2006. The E3 ubiquitin ligase itch couples JNK activation to TNF $\alpha$-induced cell death by inducing c-FLIP(L) turnover. Cell. 124:601-613.

10. Chaisson, M.L., Brooling, J.T., Ladiges, W., Tsai, S., and Fausto, N. 2002. Hepatocyte-specific inhibition of NF-кB leads to apoptosis after TNF $\alpha$-treatment, but not after partial hepatectomy. J. Clin. Invest. 110:193-202.

11. Maeda, S., et al. 2003. IKK $\beta$ is required for prevention of apoptosis mediated by cell-bound but not by circulating TNF $\alpha$. Immunity. 19:725-737.

12. Wang, Y., Singh, R., Lefkowitch, J.H., Rigoli, R.M., and Czaja, M.J. 2006. Tumor necrosis factorinduced toxic liver injury results from JNK2-dependent activation of caspase- 8 and the mitochondrial death pathway. J. Biol. Chem. 281:15258-15267.

13. Kamata, H., et al. 2005. Reactive oxygen species promote $\mathrm{TNF} \alpha$-induced death and sustained JNK activation by inhibiting MAP kinase phosphatases. Cell. 120:649-661.

14. Fausto, N., Campbell, J.S., and Riehle, K.J. 2006. Liver regeneration. Hepatology. 43: S45-S53.

15. Fausto, N. 2000. Liver regeneration. J. Hepatol. 32:19-31.

16. Taub, R. 2004. Liver regeneration: from myth to mechanism. Nat. Rev. Mol. Cell. Biol. 5:836-847.

17. Schwabe, R.F., et al. 2003. c-Jun-N-terminal kinase drives cyclin D1 expression and proliferation during liver regeneration. Hepatology. 37:824-832.

18. Stepniak, E., et al. 2006. c-Jun/AP-1 controls liver regeneration by repressing p53/p21 and p38 MAPK activity. Genes Dev. 20:2306-2314.

19. Papa, S., et al. 2004. Gadd $45 \beta$ mediates the NF-KB suppression of JNK signalling by targeting MKK7/ JNKK2. Nat. Cell Biol. 6:146-153.

20. Su, A.I., Guidotti, L.G., Pezacki, J.P., Chisari, F.V., and Schultz, P.G. 2002. Gene expression during the priming phase of liver regeneration after partial hepatectomy in mice. Proc. Natl. Acad. Sci. U. S. A. 99:11181-11186.

21. Locker, J., et al. 2003. A common set of immediate-early response genes in liver regeneration and hyperplasia. Hepatology. 38:314-325.

22. Lu, B., Ferrandino, A.F., and Flavell, R.A. 2004 Gadd $45 \beta$ is important for perpetuating cognate and inflammatory signals in T cells. Nat. Immunol. 5:38-44.

23. Gupta, M., et al. 2005. Hematopoietic cells from Gadd $45 \alpha$-and Gadd $45 \beta$-deficient mice are sensitized to genotoxic-stress-induced apoptosis. Oncogene. 24:7170-7179.

24. Mangnall, D., Bird, N.C., and Majeed, A.W. 2003. The molecular physiology of liver regeneration following partial hepatectomy. Liver Int. 23:124-138.

25. Sakurai, T., Maeda, S., Chang, L., and Karin, M. 2006. Loss of hepatic NF- $\mathrm{KB}$ activity enhances chemical hepatocarcinogenesis through sustained c-Jun N-terminal kinase 1 activation. Proc. Natl. Acad. Sci. U. S. A. 103:10544-10551.

26. Yamada, Y., Kirillova, I., Peschon, J.J., and Fausto, N. 1997. Initiation of liver growth by tumor necrosis factor: deficient liver regeneration in mice lack- ing type I tumor necrosis factor receptor. Proc. Natl. Acad. Sci. U. S. A. 94:1441-1446.

27. Pikarsky, E., et al. 2004. NF-кB functions as a tumour promoter in inflammation-associated cancer. Nature. 431:461-466.

28. Wullaert, A., van Loo, G., Heyninck, K., and Beyaert, R. 2007. Hepatic tumor necrosis factor signaling and nuclear factor- $\mathrm{\kappa B}$ : effects on liver homeostasis and beyond. Endocr. Rev. 28:365-386.

29. Iimuro, Y., et al. 1998. NF-кB prevents apoptosis and liver dysfunction during liver regeneration. J. Clin. Invest. 101:802-811.

30. Maeda, S., Kamata, H., Luo, J.L., Leffert, H., and Karin, M. 2005. IKK $\beta$ couples hepatocyte death to cytokine-driven compensatory proliferation that promotes chemical hepatocarcinogenesis. Cell. 121:977-990.

31. Luedde, T., et al. 2007. Deletion of NEMO/IKK $\gamma$ in liver parenchymal cells causes steatohepatitis and hepatocellular carcinoma. Cancer Cell. 11:119-132.

32. Tournier, C., et al. 2000. Requirement of JNK for stress-induced activation of the cytochrome c-mediated death pathway. Science. 288:870-874.

33. Jaeschke, A., et al. 2006. JNK2 is a positive regulator of the cJun transcription factor. Mol. Cell. 23:899-911.

34. Nelsen, C.J., et al. 2001. Transient expression of cyclin D1 is sufficient to promote hepatocyte replication and liver growth in vivo. Cancer Res. 61:8564-8568.

35. Pham, C.G., et al. 2004. Ferritin heavy chain

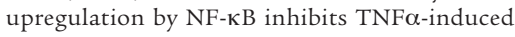
apoptosis by suppressing reactive oxygen species. Cell. 119:529-542.

36. Yang, D.D., et al. 1998. Differentiation of CD4+ T cells to Th1 cells requires MAP kinase JNK2. Immunity. 9:575-585.

37. Anders, R.A., Subudhi, S.K., Wang, J., Pfeffer, K., and Fu, Y.X. 2005. Contribution of the lymphotoxin beta receptor to liver regeneration. J. Immunol. 175:1295-1300.

38. Pham, C.G., et al. 2007. Upregulation of Twist-1 by NF-kB blocks cytotoxicity induced by chemotherapeutic drugs. Mol. Cell. Biol. 27:3920-3935. 